\title{
A Force Field and a Surface Model Database for Silica to Simulate Interfacial Properties in Atomic Resolution
}

by

Fateme S. Emami ${ }^{\dagger}$, Valeria Puddu ${ }^{\ddagger}$, Rajiv J. Berry ${ }^{\S}$, Vikas Varshney ${ }^{\S}$, Siddharth V. Patwardhan", Carole C. Perry ${ }^{\ddagger^{*}}$, and Hendrik Heinz ${ }^{\dagger *}$

† Department of Polymer Engineering, University of Akron, Akron, Ohio 44325-0301, USA

$\$$ Interdisciplinary Biomedical Research Centre, School of Science and Technology, Nottingham Trent University, Clifton Lane, Nottingham NG11 8NS, UK

$\S$ Materials and Manufacturing Directorate, Air Force Research Laboratory, Wright-Patterson Air Force Base, Ohio 45433, USA

" Department of Chemical and Process Engineering, University of Strathclyde, 75 Montrose Street, Glasgow G1 1XJ, UK

* Corresponding authors: carole.perry@ntu.ac.uk, hendrik.heinz@uakron.edu 


\begin{abstract}
Silica nanostructures find applications in drug delivery, catalysis, and composites, however, understanding of the surface chemistry, aqueous interfaces, and biomolecule recognition remain difficult using current imaging techniques and spectroscopy. A silica force field is introduced that resolves numerous shortcomings of prior silica force fields over the last thirty years and reduces uncertainties in computed interfacial properties relative to experiment from several $100 \%$ to less than $5 \%$. In addition, a silica surface model database is introduced for the full range of variable surface chemistry and $\mathrm{pH}\left(\mathrm{Q}^{2}, \mathrm{Q}^{3}, \mathrm{Q}^{4}\right.$ environments with adjustable degree of ionization) that have shown to determine selective molecular recognition. The force field enables accurate computational predictions of aqueous interfacial properties of all types of silica, which is substantiated by extensive comparisons to experimental measurements. The parameters are integrated into multiple force fields for broad applicability to biomolecules, polymers, and inorganic materials (AMBER, CHARMM, COMPASS, CVFF, PCFF, INTERFACE force field). We also explain mechanistic details of molecular adsorption of water vapor, as well as significant variations in the amount and dissociation depth of superficial cations at silica-water interfaces that correlate with zeta-potential measurements and create a wide range of aqueous environments for adsorption and self-assembly of complex molecules. The systematic analysis of binding conformations and adsorption free energies of distinct peptides to silica surfaces is reported separately in a companion paper. The models aid to understand and design silica nanomaterials in $3 \mathrm{D}$ atomic resolution, and are extendable to chemical reactions.
\end{abstract}




\section{Introduction}

Silicon dioxide, or silica, is widely available in nature, by technical synthesis, and biologically enriched in various organisms. ${ }^{1-3}$ Silica is used as filler in nanocomposites and tires, ${ }^{4-6}$ for purification of gases and liquids, ${ }^{7,8}$ as well as in catalyst supports. ${ }^{9-11}$ More recently, silica nanoparticles find applications in drug delivery, biosensors, and cosmetics that exploit interactions with biological molecules in aqueous solution. ${ }^{12-15}$ Diatoms in marine environments also produce hierarchically organized silica-protein skeletons, ${ }^{16-18}$ and laboratory efforts have aimed at replications using designed amino acid sequences. ${ }^{19-25}$ Success in terms of achievable order of silica nanostructures has yet been limited, even though several peptides and proteins isolated from microorganisms and cellular templates were employed. ${ }^{19,21,22,26-30}$ Engineering complex silica-containing materials requires quantitative understanding of the role of the silica precursors, surface chemistry of silica formed, as well as competitive interactions with solvents and proteins. The effect of $\mathrm{pH}$, molecular conformation, and buffer composition on materials properties is thereby critical. ${ }^{19,31,32}$ Overall, many questions related to silica biomineralization, specific molecular recognition, and interfacial adhesion remain difficult to answer using available instrumentation. Molecular simulation can provide missing insight and accelerate rational materials design, and reliable tools for such simulations are needed.

The simulation of bulk and surface properties of silica has been of interest since the emergence of numerical computer methods in the 1980s (Table 1). ${ }^{33-43 r 88, r 09}$ Numerous developments have occurred over the years and substantial shortcomings still persist (section S1 for details). Early force fields often assumed overly ionic Si-O bonds, and surface models containing functional groups such as silanol $(\mathrm{SiOH})$ and siloxide $\left(\mathrm{SiO}^{-} \mathrm{Na}^{+}\right)$were not feasible. ${ }^{33,34 r 88}$ Subsequent models introduced covalent bonds and more broadly applicable energy expressions. ${ }^{35,36,39,40,44}$ Nevertheless, surface properties continued to deviate up to 
multiples from experimental data and the chemical variety of silica surfaces, including surface ionization in particular, was not taken into account. Additional shortcomings include shrinkage over $20 \%$ in some models and errors in stoichiometry. ${ }^{36,39,40}$ Similar difficulties are also encountered in reactive force fields that employ less compatible, highly complex energy expressions. ${ }^{45}$ A key step towards chemical precision of atomistic models has been the careful evaluation of the correct balance of covalent bonding versus ionic bonding, which is reflected by atomic charges of $+1.1 \pm 0.1 \mathrm{e}$ for $\mathrm{Si}$ in tetrahedral oxygen coordination. ${ }^{46}$ Structural properties, surface, and hydration energies can then be computed in agreement with measurements. ${ }^{47}$ At the same time, the observation of silica surface chemistry and $\mathrm{pH}$ conditions in the model is paramount. ${ }^{19,48}$ Specifically, the area density of silanol groups $(\equiv \mathrm{SiOH})$ and the degree of ionization of silanol groups to siloxide groups (e.g. $\left.\equiv \mathrm{SiO}^{-} \cdots \mathrm{Na}^{+}\right)$are critical. The area density of silanol groups can vary between 0 and 9.4 groups per $\mathrm{nm}^{2}{ }^{49}$ and ionization to siloxide groups in the range of 0.0 to 2.0 ionized groups per $\mathrm{nm}^{2}$ has been observed by potentiometric titration depending on type of surface, $\mathrm{pH}$, ionic strength, and type of cation. ${ }^{19,50-53}$

The aim of this contribution is the introduction of a silica surface model database that covers all types of surface chemistry and $\mathrm{pH}$, as well as the introduction of a silica force field that resolves limitations of prior models. Our team has previously proposed accurate force fields for related minerals, in comparison to which silica is a relatively simple case..$^{19,46-48,54,55}$ The current model provides complete understanding of all parameters and increases the computed accuracy of many properties by an order of magnitude, including silica-water and silica-organic interfaces. The main features are: (1) full atom mobility, (2) match of computed and experimental cell parameters, (3) good match of computed and measured density of states (IR, Raman), (4) full range of silica surface models with $\mathrm{Q}^{2}, \mathrm{Q}^{3}, \mathrm{Q}^{4}$ surface environments and interpretation in the 
context of experiment, (5) full range of surface ionization corresponding to $\mathrm{pH}$ and surface type/particle size, (6) match of computed and measured immersion energies of $\mathrm{Q}^{3}$ surfaces (pyrogenic silica) in water, (7) consistency of computed and measured adsorption isotherms of water on $\mathrm{Q}^{3}$ surfaces, (8) match of water contact angles on surfaces between $\mathrm{Q}^{3}$ to $\mathrm{Q}^{4}$ type, (9) agreement of the amount of dissociated cations with zeta potentials on ionized $\mathrm{Q}^{3}$ surfaces as a function of $\mathrm{pH}$ and particle size, (10) quantitative correlation between computed and measured peptide adsorption on ionized $\mathrm{Q}^{3}$ and $\mathrm{Q}^{2} / \mathrm{Q}^{3}$ surfaces for peptides carrying various charges (see ref. $\left.{ }^{56}\right)$, (11) compatibility of the force field with major organic and biomolecular force fields $\left(\mathrm{CHARMM},{ }^{57} \mathrm{CVFF}^{58}{ }^{5 \mathrm{AMBER}},{ }^{59} \mathrm{PCFF}^{35,60-62} \mathrm{COMPASS}^{63}{ }^{63} \mathrm{INTERFACE}^{48}\right.$ ), (12) low number and full interpretation of force field parameters.

This paper focuses on the introduction of the silica models and provides full validation for aqueous interfaces. Accurate data for adsorption of various peptides are reported in a companion paper to maintain reasonable length. ${ }^{56}$ In section 2 , we discuss the surface model database and the construction of model surfaces for given chemical conditions and $\mathrm{pH}$. In section 3 , we describe the force field and structural validation. In section 4, properties of solid-liquid, solidvapor interfaces, and electric double layers are analyzed in comparison to measurements. Conclusions follow in section 5. Computational methods and further details are provided in the Supporting Information. 
Table 1. Comparison of essential performance characteristics of silica force fields.

\begin{tabular}{|c|c|c|c|c|c|c|}
\hline & $\begin{array}{l}\text { Potential } \\
\text { function }\end{array}$ & $\begin{array}{l}\text { Bulk Si } \\
\text { charge (e) }\end{array}$ & $\begin{array}{l}\text { Surface } \mathrm{SiOH} \\
\qquad\left(\mathrm{OH} / \mathrm{nm}^{2}\right)\end{array}$ & $\begin{array}{l}\mathrm{SiOH} \\
\text { ionization }(\%)\end{array}$ & $\begin{array}{c}\text { Atom } \\
\text { mobility }\end{array}$ & $\begin{array}{c}\Delta \mathrm{H}_{\mathrm{imm}}\left(\mathrm{Q}^{3}\right) \\
\left(\mathrm{mJ} / \mathrm{m}^{2}\right)\end{array}$ \\
\hline Experiment & & $+1.1 \pm 0.1^{\mathrm{a}}$ & 0 to 9.4 & $0-25 \%^{b}$ & & $160 \pm 5^{c}$ \\
\hline Present study & 9-6/12-6 LJ & +1.1 & 0 to 9.4 & $0-25 \%$ & $\checkmark$ & $167 \pm 2^{c}$ \\
\hline Butenuth et al. ${ }^{40}$ & $12-6 \mathrm{LJ}$ & +1.6 & 4.4 & Not reported & $x^{d}$ & $178 \pm 5^{\mathrm{c}}$ \\
\hline Hassanali et al. ${ }^{37}$ & Buckingham & +2.4 & $4,6.4$ & $0 \%$ & $\checkmark$ & $280,830 \pm 5^{c}$ \\
\hline Lopes et al. ${ }^{39}$ & $12-6 \mathrm{LJ}$ & +1.08 & $4,9.3^{\mathrm{e}}$ & $0 \%$ & $x^{f}$ & $>1000^{c}$ \\
\hline Cruz-Chu et al. ${ }^{36}$ & $12-6 \mathrm{LJ}$ & +1.0 & Non-stochiometric ${ }^{\mathrm{g}}$ & No ionization ${ }^{\mathrm{g}}$ & $x$ & NA \\
\hline Beest et al. ${ }^{34}$ & Buckingham & +2.4 & NA (bulk only) & NA & $\checkmark$ & NA \\
\hline Hill and Sauer ${ }^{35}$ & 9-6 LJ & +0.5 & Full range possible & $0 \%$ & $\checkmark$ & $<0^{\mathrm{h}}$ \\
\hline Catlow $^{33}$ & Buckingham & +4.0 & NA (bulk only) & NA & $\checkmark$ & NA \\
\hline Feuston et al. ${ }^{\mathrm{r} 88}$ & $\begin{array}{l}\text { BMH, SW } \\
\text { potential }\end{array}$ & +4.0 & NA & NA & $\checkmark$ & NA \\
\hline \multicolumn{7}{|c|}{$\begin{array}{l}{ }^{\text {a }} \text { Refs. }{ }^{46,64-66} \cdot{ }^{\mathrm{b}} \text { Ionization to } \mathrm{SiO}^{-} \mathrm{Na}^{+} \text {groups varies from } 0 \text { to } \sim 2.0 \text { per } \mathrm{nm}^{2} \text { as a } \\
\text { function of surface characteristics (cleavage plane, particle size, porosity), } \mathrm{pH} \text {, and }\end{array}$} \\
\hline \multicolumn{7}{|c|}{${ }^{\mathrm{c}}$ Pyrogenic silica in pure water, ref. ${ }^{72} .{ }^{\mathrm{d}}$ More than $30 \%$ shrinkage in comparison to X- } \\
\hline \multicolumn{7}{|c|}{ ray data when atom positions are not fixed. ${ }^{\mathrm{e}}$ Quartz (011) and (100) surfaces. ${ }^{\mathrm{f}}$ More } \\
\hline $\mathrm{Si}$ and $\mathrm{O}$ & have multiple & Jalencies, su & $\mathrm{ch}$ as $\mathrm{Si}$ atoms with thr & ee bonds and $\mathrm{O}$ a & toms with & \\
\hline
\end{tabular}


parameters for superficial $\mathrm{Si}$ and $\mathrm{O}$ are given. The atomic charge for silanol $\mathrm{H}$ is very low $(+0.0657 e)$. 


\section{A Silica Surface Model Database}

Our team has previously shown that differences in the surface structure of various silica nanoparticles are so substantial that combinatorially attracted peptides exhibit less than $20 \%$ sequence similarity at comparable $\mathrm{pH}$ and ionic strength. ${ }^{19,73-76}$ Sequence similarity is entirely random $(5 \%)$ when the $\mathrm{pH}$ value varies in addition. Specific models for a given type of silica and conditions in solution are thus essential ${ }^{19}$ and proposed here to cover the range of possible surface chemistry and ionization (Table 2). Similar diversity of surface environments is also expected for other oxides such as titania and apatites, however, not for precious metals that are of simple chemistry and attract similar peptide sequences. ${ }^{77-83}$

Two major factors play a role for the construction of a silica surface model. One is the type of substrate that determines the area density of silanol groups; the other is the degree of ionization (Table 2). Silica exists in various crystalline polymorphs, e.g., quartz, tridymite, cristobalite, stishovite, and amorphous phases, e.g., silica gel, precipitated silica, fumed silica particles, and porous glasses., ${ }^{2,84-86}$ These forms of silica exhibit different bulk, surface, and physiological properties. The surfaces of the many types of silica have been extensively characterized, and such information has rarely found entry into appropriate molecular models to date (some are given in the Interface force field ${ }^{48}$ ). The most common techniques for surface characterization are measurements of the specific surface area (BET) combined with measurements of weight loss upon heating to determine the area density of silanol groups, ${ }^{49,87,88}$ measurements of contact angles, ${ }^{89,90}$ immersion energies, ${ }^{72,91-93}$ adsorption isotherms, ${ }^{94,95}$ solid state NMR spectroscopy, ${ }^{96}$ infrared (IR) and Raman spectroscopy, ${ }^{19,97,98}$ X-ray photoelectron spectroscopy (XPS), ${ }^{99}$ as well as potentiometric titration ${ }^{50-53,67-71}$ and $\zeta$-potential measurements. ${ }^{19}$ Potentiometric titration and $\zeta$-potential measurements are critical to quantify surface ionization 
as a function of $\mathrm{pH}$ and ionic strength. The available redundant information provides excellent guidance to build realistic surface models that are essential for predictive simulations (Figure 1 and Supporting Information).

2.1. Type of Substrate and Area Density of Silanol Groups. Some hydrated cleavage planes of quartz, surfaces of large silica nanoparticles, and various forms of silica at high $\mathrm{pH}$ contain $\mathrm{Q}^{2}$ surface environments, i.e., two silanol groups per superficial silicon atom $\left(=\mathrm{Si}(\mathrm{OH})_{2}\right)$, and mixed $\mathrm{Q}^{2} / \mathrm{Q}^{3}$ surface environments. The area density of silanol groups is then in the upper range of 9.4 to 4.7 per $\mathrm{nm}^{2}$ (Figure 1e). Most silica glasses, porous glasses, and medium size nanoparticles $(\sim 100 \mathrm{~nm})$ contain $70-90 \% \mathrm{Q}^{3}$ environments on the surface $((\equiv \mathrm{Si}(\mathrm{OH}))$, i.e., one silanol group per superficial silicon atom (Figure 1 a-d). The remainder of 10-30\% is comprised of $\mathrm{Q}^{2}$ and $\mathrm{Q}^{4}$ environments. The average area density of surface silanol groups in aqueous amorphous silica is $4.5-4.9$ per $\mathrm{nm}^{2}$, whereby 4.7 silanol groups per $\mathrm{nm}^{2}$ coincides with the area density of a perfect $\mathrm{Q}^{3}$ silica surface. ${ }^{49,87}$ Silica surfaces after thermal treatment feature a higher proportion of $\mathrm{Q}^{4}$ environments, i.e., siloxide bridges without silanol groups (Figure 1f). The type and area density of silanol groups thus depends on the chosen crystal cleavage plane, particle size, synthesis protocol, thermal pretreatment, humidity, and aging. In addition, surface roughness and porosity can be important for a given model and implemented by processing models of the corresponding even surfaces.

2.2. Ionization of Silanol Groups. All silanol groups on the surface ( $\mathrm{SiOH})$ are subject to deprotonation-protonation equilibria. Neutral silanol terminated surfaces are found at $\mathrm{pH}$ values between 2 and 4 (point of zero charge) and partial conversion into metal siloxide groups $\mathrm{SiO}^{-} \ldots$ $\mathrm{M}^{+}$occurs with solution electrolytes as a function of substrate type, $\mathrm{pH}$, ionic strength, and type of cations (Table 2). $\mathrm{M}^{+}$can be an alkali cation or the equivalent of other cations. The common 
range is between 0 and $1.0 \mathrm{SiO}^{-} \cdots \mathrm{M}^{+}$groups per $\mathrm{nm}^{2}$, corresponding to between 0 and $20 \%$ ionization on a $\mathrm{Q}^{3}$ surface, and less than 2.0 siloxide groups per $\mathrm{nm}^{2}$ for any type of silica surface. In general, ionization increases from $\mathrm{Q}^{4}$ towards $\mathrm{Q}^{2}$ environments, toward higher $\mathrm{pH}$ (in hyperbolic form), and toward higher ionic strength. The precise extent of ionization per unit surface area depends on (1) the area density $\left(\mathrm{Q}^{2}, \mathrm{Q}^{3}, \mathrm{Q}^{4}\right)$ and type of silanol groups (geminal, vicinal, isolated, occluded in pores), ${ }^{2,19,85,94}$ (2) $\mathrm{pH}$, (3) ionic strength of the solution, (4) and the type of cations and anions present in solution. ${ }^{50-53,67-71}$ As an example, the sensitivity of surface ionization is graphically illustrated for common amorphous silica nanoparticles prepared by Stöber-like synthesis (Figure 2). ${ }^{19}$

The type of surface and $\mathrm{pH}$ are key factors for surface ionization. However, the role of ionic strength is also critical. For example, when freshly cleaved crystal surfaces or freshly synthesized pyrogenic silica nanoparticles (Figure S1) are immersed in ultrapure water of an ionic strength $I<10^{-3} \mathrm{M}$, practically no ionization occurs because buffers and stabilizing metal ions are absent $(<1 \%){ }^{50,52,67,69}$ This is important for a range of measurements such as immersion energies, contact angles, and adsorption isotherms that are reported as part of force field validation (section 4). Under conditions in the human body and during biomimetic synthesis, ionization is close to the levels shown in Table 2. The precise amount of ionization for a desired model should thus always be determined using data in the original literature s0-53,67-71 $^{\text {or direct }}$ experimental measurements.

2.3. Model Choices and Validity. Overall, it has been demonstrated that the silanol area density and the degree of ionization can both vary more than an order of magnitude, underlining that the choice of suitable surface models is greatly important (Table 2). At the same time, experimental data also suggest that minor differences have limited impact and are not a reason 
for concern. Numerous previous ${ }^{19}$ and present simulations of silica interfaces have confirmed that results differ enormously for the extremes, although the sensitivity to small changes is not high. With this insight in mind, we developed a surface model database that contains over twenty different silica models to enable informed choices (see Supporting Information). To achieve quantitative correlations with measurements, the chosen area density of silanol groups should

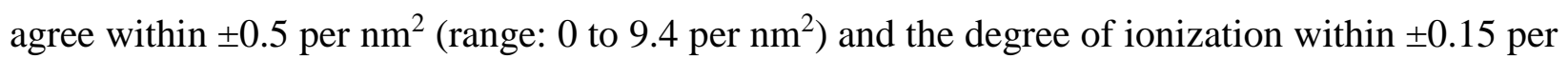
$\mathrm{nm}^{2}$ (range: 0 to $\sim 2.0$ per $\mathrm{nm}^{2}$ ) with a true sample. The example of common amorphous silica nanoparticles illustrates this argument (Figure 2) ${ }^{19}$

Details of the construction of models are fully described in section S9 of the SI. The distribution of ionized sites $\left(\mathrm{SiO}^{-} \mathrm{Na}^{+}\right)$in the surface model database was chosen corresponding to the minimum energy and dynamic proton distributions could become feasible using constant pH molecular dynamics. ${ }^{100}$ Available models can be further customized for particular ionic environments, porous, and other morphologies, especially when sample-specific data are available (see further discussion in section S2). 

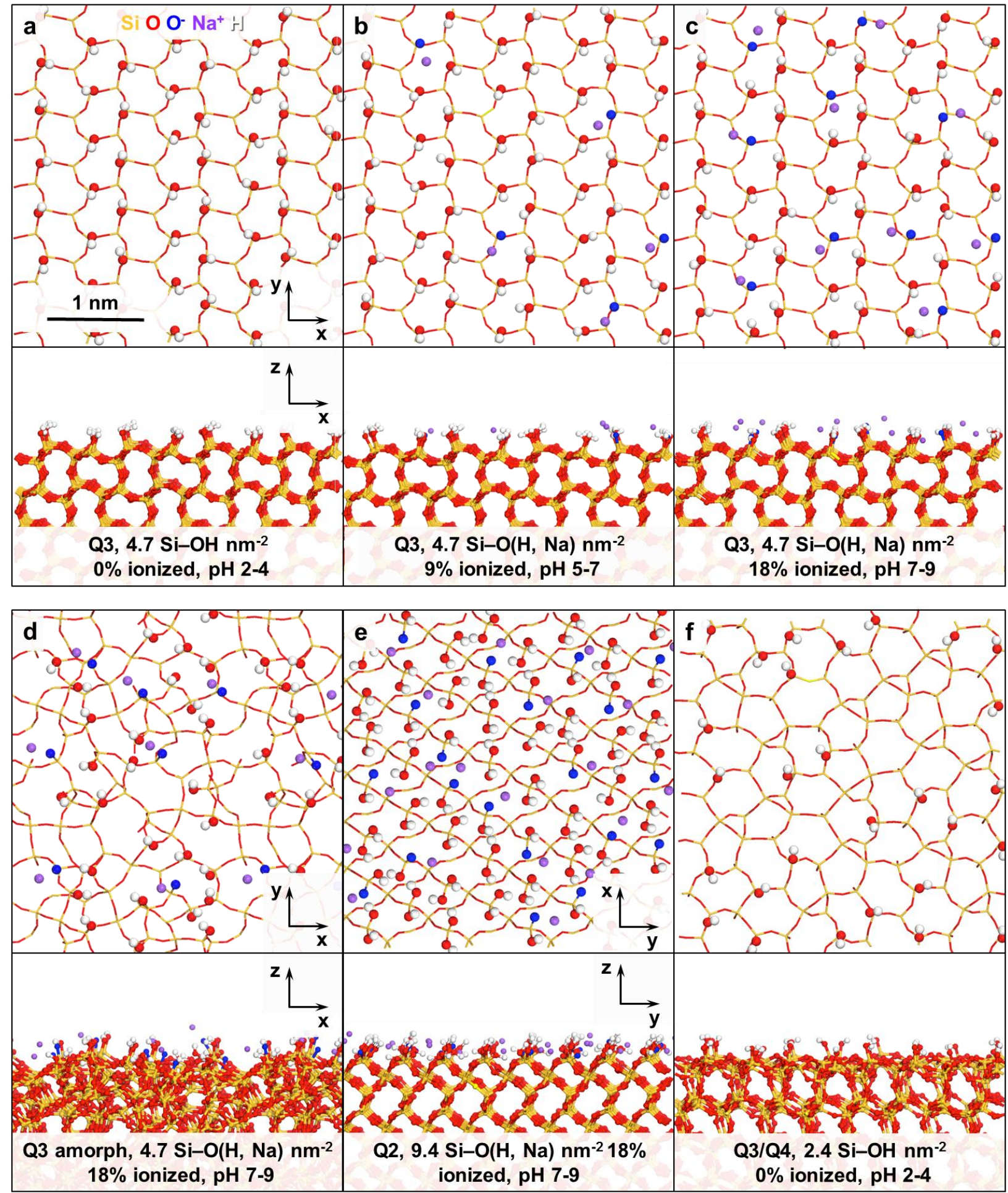

Figure 1. Representative models of silica surfaces. (a-c) Regular $\mathrm{Q}^{3}$ surfaces with a total Si$\mathrm{O}(\mathrm{H}, \mathrm{Na})$ density of $4.7 \mathrm{~nm}^{-2}$ and $0 \%, 9 \%$, and $18 \%$ ionization in top view (upper panel) and side view (lower panel). The models are suitable for silica at different $\mathrm{pH}$ and particle size. (d-f) More 
specialized surfaces in top view (upper panel) and side view (lower panel). (d) Amorphous $\mathrm{Q}^{3}$ silica surface with a total $\mathrm{Si}-\mathrm{O}(\mathrm{H}, \mathrm{Na})$ density of $4.7 \mathrm{~nm}^{-2}$ and $18 \%$ ionization, similar to (c). (e) Regular $\mathrm{Q}^{2}$ surface with a total $\mathrm{Si}-\mathrm{O}(\mathrm{H}, \mathrm{Na})$ density of $9.4 \mathrm{~nm}^{-2}$ and $18 \%$ ionization. (f) Annealed $50: 50 \mathrm{Q}^{3} / \mathrm{Q}^{4}$ surface with a total $\mathrm{Si}-\mathrm{O}(\mathrm{H}, \mathrm{Na})$ density of $2.4 \mathrm{~nm}^{-2}$ at the point of zero charge. Surface ionization and $\mathrm{pH}$ relate to an ionic strength of $0.1-0.3 \mathrm{~mol} \cdot \mathrm{dm}^{-3}$ near physiological conditions.

Table 2. Guide towards surface models for a given silica substrate, as implemented in the silica surface model database. Essential information includes the area density of $\mathrm{SiO}(\mathrm{H}, \mathrm{Na})$ groups, the degree of ionization, and the surface topography.

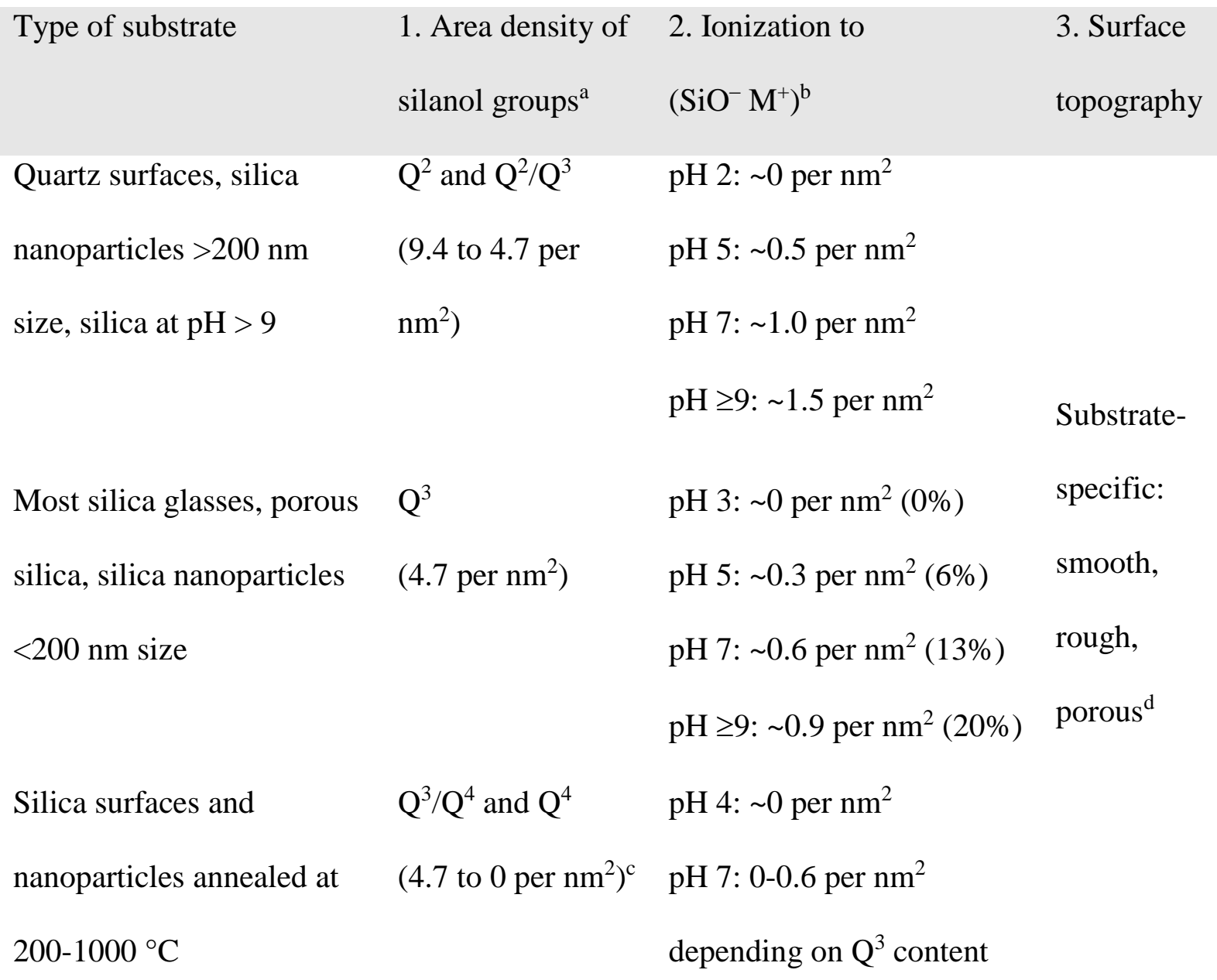


a The area density and specific changes from $\mathrm{Q}^{2}$ to $\mathrm{Q}^{4}$ at high temperatures are described in refs. ${ }^{49,88}$. ${ }^{\mathrm{b}}$ We assume physiological conditions with an ionic strength $I \sim 0.1-0.3 \mathrm{M}$ of sodium ions. Ionization at a given $\mathrm{pH}$ for different ionic strength $I$ and other cations must be reevaluated according to data in refs. ${ }^{19,50-53,67-71}$. Also, silica begins to dissolve at $\mathrm{pH} \geq 9 .{ }^{\mathrm{c}}$ Rehydration can lower the $\mathrm{Q}^{4}$ content in favor of $\mathrm{Q}^{3}$. ${ }^{\mathrm{d}}$ Pore parameters include pore diameter, depth, and area density of pores on the surface. Narrow pores likely reduce ionization.

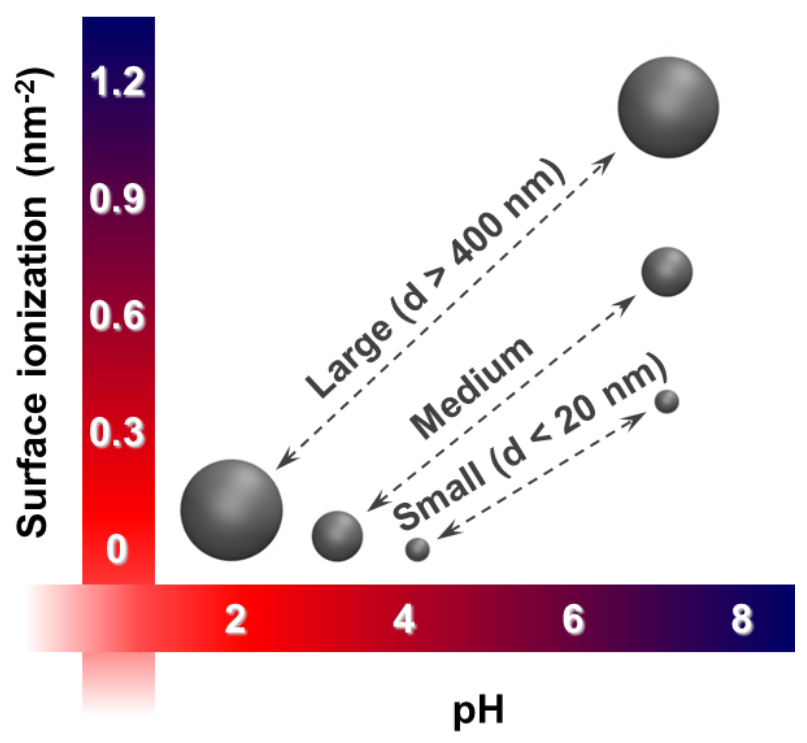

Figure 2. Schematic relationship between surface ionization and $\mathrm{pH}$ for amorphous silica nanoparticles from Stöber-type synthesis. Large nanoparticles contain $\mathrm{Q}^{2} / \mathrm{Q}^{3}$ surface environments, medium and smaller nanoparticles mostly $\mathrm{Q}^{3}$ environments. The amount of $\mathrm{SiO}^{-}$ $\mathrm{Na}^{+}$groups per $\mathrm{nm}^{2}$ is shown at an ionic strength of $0.1-0.3 \mathrm{~mol} \cdot \mathrm{dm}^{-3}$ (see details and original data in refs. ${ }^{19,50-53}$ ). 


\section{Force Field Parameters and Structural Validation}

3.1. Choice of Functional Form. We choose common harmonic energy expressions that are suitable for inorganic compounds and allow accurate simulations of interfaces with water, biomolecules, and polymers. ${ }^{47,48,101} \mathrm{We}$ aim at broad applicability using multiple platforms, including CHARMM, CVFF, AMBER (equation 1), PCFF, and COMPASS (equation 2):

$$
\begin{aligned}
& E_{\text {pot }}=\sum_{\substack{i j, \text { non bonded } \\
1,2 \text { and } 1,3 \text { excl }}} \varepsilon_{i j}\left[\left(\frac{\sigma_{i j}}{r_{i j}}\right)^{12}-2\left(\frac{\sigma_{i j}}{r_{i j}}\right)^{6}\right]+\frac{1}{4 \pi \varepsilon_{0}} \sum_{\begin{array}{c}
i j, \text { non bonded } \\
1,2 \text { and } 1,3 \text { excl }
\end{array}} \frac{q_{i} q_{j}}{r_{i j}} \\
& +\sum_{i j, \text { bonded }} k_{r, i j} \cdot\left(r_{i j}-r_{0, i j}\right)^{2}+\sum_{i j k, \text { bonded }} k_{i j k} \cdot\left(\theta_{i j k}-\theta_{0, i j k}\right)^{2}
\end{aligned}
$$$$
\text { CHARMM, CVFF, AMBER }
$$

$$
\begin{aligned}
& E_{\text {pot }}=\sum_{\substack{i j, \text { non bonded } \\
1,2 \text { and } 1,3 \text { excl }}} \varepsilon_{i j}\left[2\left(\frac{\sigma_{i j}}{r_{i j}}\right)^{9}-3\left(\frac{\sigma_{i j}}{r_{i j}}\right)^{6}\right]+\frac{1}{4 \pi \varepsilon_{0}} \sum_{\substack{i j, \text { non bonded } \\
1,2 \text { and } 1,3 \text { excl }}} \frac{q_{i} q_{j}}{r_{i j}} \\
& +\sum_{i j, \text { bonded }} k_{r, i j} \cdot\left(r_{i j}-r_{0, i j}\right)^{2}+\sum_{i j k, \text { bonded }} k_{\theta, i j k} \cdot\left(\theta_{i j k}-\theta_{0, i j k}\right)^{2}
\end{aligned}
$$

PCFF, COMPASS

The potential energy $E_{p o t}$ contains 12-6 and 9-6 Lennard-Jones potentials for repulsive and dispersive van-der-Waals interactions, respectively, a Coulomb potential for electrostatic interactions, as well as harmonic potentials for bond stretching and angle bending. Torsion potentials are not necessary due to the limited number of rotational degrees of freedom.

The functional forms in equation 1 and equation 2 exhibit some differences, for example, in 12-6 versus 9-6 exponentials of the Lennard-Jones (LJ) potential, in combination rules to obtain ${ }_{i j}$ and ${ }_{i j}$ for pairs of different atom types $i$ and $j$, as well as in conventions for scaling of 
nonbond interactions between 1,4 bonded atoms. These differences were accounted for by adjusted parameter sets for each force field (Tables 3 and 4) and tests to achieve near-identical performance. Furthermore, some default energy terms in the mentioned force fields are not needed for silica, such as Urey-Bradley, torsion, and out-of-plane potentials in class I force fields (CHARMM, CVFF, AMBER), as well as higher order cubic, quartic, and cross terms in class II force fields (PCFF, COMPASS). ${ }^{47,48,101}$ The presence of such terms for other molecules does not interfere with the silica parameters.

3.2. Force Field Parameters. The parameters for nonbonded and bonded interactions are listed in Table 3 and Table 4 for all energy expressions. We distinguish five atom types consistent with different chemical environments, which are sufficient to describe bulk and surface properties in excellent agreement with experimental measurements (Figure 3). ${ }^{46,48,55}$ The atom types include silicon, bulk oxygen, silanol oxygen, hydrogen, and sodium. All atoms possess nonbonded terms (Table 3). Bonded terms are included between neighboring atoms with predominantly covalent character, i.e., silicon-oxygen bonds with atomic charges of $+1.1 \pm 0.1 \mathrm{e}$ for $\mathrm{Si}$ in tetrahedral oxygen coordination as well as oxygen-hydrogen bonds in silanol groups (Table 4). ${ }^{46,47}$

The silica parameters are compatible with TIP3P and flexible SCP water models, leading to $<5 \%$ difference in interfacial properties, as well as with parameters for biomacromolecules, surfactants, and polymers in CHARMM, CVFF, AMBER, PCFF, and COMPASS using standard combination rules (Tables 3 and 4). Among the force fields with 12-6 potentials (equation 1), silica parameters for CHARMM and CVFF are identical since arithmetic versus geometric combination rules for ${ }_{i j}$ cause only a negligible difference. Silica parameters for CHARMM and AMBER are identical except for the $\mathrm{Si}-\mathrm{O}$ equilibrium bond length $r_{0, i j}(1.68 \AA$ for 
CHARMM and $1.65 \AA$ for AMBER). The shorter bond length $r_{0, i j}$ in AMBER compensates for the partial reduction of nonbond interactions between 1,4 bonded atoms through the scaling factor of 0.5 for $\mathrm{LJ}$ and $5 / 6$ for Coulomb interactions versus the scaling factor of 1.0 for both in other force fields. The different values of $r_{0, i j}$ lead to the same average $\mathrm{Si}-\mathrm{O}$ bond length of 1.61 $\AA$ in MD simulation at $298 \mathrm{~K}$, in agreement with X-ray data for all energy expressions. ${ }^{102,103}$ PCFF and COMPASS require different ${ }_{i i}$ and ${ }_{i i}$ values due to a less repulsive 9-6 LJ potential. ${ }^{47,104}$

Table 3. Non-bonded parameters for silica and silica surfaces.

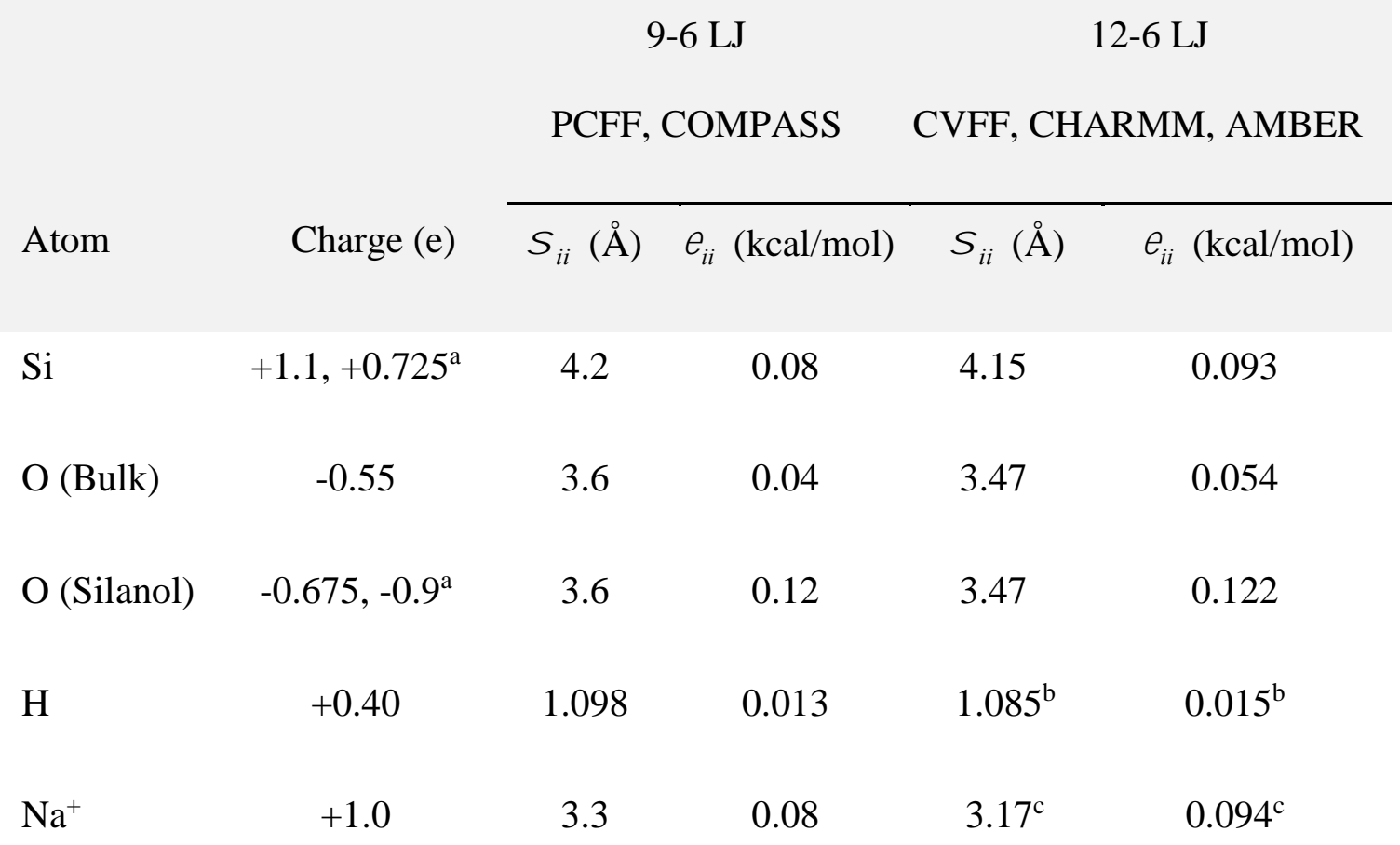

${ }^{a}$ Sodium siloxide groups require $+0.725 e$ for $\mathrm{Si}$ and $-0.9 e$ for $\mathrm{O}$ (Figure 3).

${ }^{\mathrm{b}} \mathrm{LJ}$ parameters for silanol hydrogen $\left({ }_{i i}, \quad i i\right)$ can also be set to zero as in water hydrogen in SPC and TIP3P models. The computed heat of immersion changes $<5 \mathrm{~mJ} \cdot \mathrm{m}^{-2}(<3 \%)$. 
${ }^{\mathrm{c}}$ We recommend these 12-6 LJ parameters $\left({ }_{i i},{ }_{i i}\right)$ for sodium ions (ref. $\left.{ }^{48}\right)$. The computed hydration energy of $-95 \pm 5 \mathrm{kcal} / \mathrm{mol}$ at $298 \mathrm{~K}$ agrees with measurements of $-97 \mathrm{kcal} / \mathrm{mol}$ at infinite dilution (ref. ${ }^{105}$ ). Alternative parameters are available in CHARMM (2.7275 $\AA, 0.0469$ $\mathrm{kcal} / \mathrm{mol})$ (ref. $\left.{ }^{106}\right)$ and AMBER $(2.738 \AA, 0.0874 \mathrm{kcal} / \mathrm{mol})\left(\right.$ ref. ${ }^{107}$ ), whereby the listed $\mathrm{Na}^{+}$ diameter ${ }_{i i}$ of $2.73 \AA$ appears small in comparison to $3.087 \AA$ for isoelectronic $\mathrm{Ne}$ (ref. ${ }^{108}$ ), especially upon added contraction by strong Coulomb forces with water and other species.

Table 4. Bonded parameters for silica and silica surfaces.

\begin{tabular}{|c|c|c|}
\hline \multirow[b]{2}{*}{ Type } & \multicolumn{2}{|c|}{ Bond: $E_{r}=k_{r}\left(r_{i j} \quad r_{0, i j}\right)^{2}$} \\
\hline & $k_{r}\left(\mathrm{kcal} /\left(\mathrm{mol} \cdot \AA^{2}\right)\right)$ & $r_{0, i j}(\AA)$ \\
\hline $\mathrm{Si}-\mathrm{O}$ & 285 & $1.68,1.65^{\mathrm{a}}$ \\
\hline $\mathrm{O}-\mathrm{H}$ & 495 & 0.945 \\
\hline \multirow{2}{*}{ Type } & Angle: $E=k($ & $0, i j k)^{2}$ \\
\hline & $k \quad\left(\mathrm{kcal} /\left(\mathrm{mol} \cdot \mathrm{rad}^{2}\right)\right)$ & ${ }_{0}\left({ }^{\circ}\right)$ \\
\hline $\mathrm{O}-\mathrm{Si}-\mathrm{O}$ & 100 & 109.5 \\
\hline $\mathrm{Si}-\mathrm{O}-\mathrm{Si}$ & 100 & 149.0 \\
\hline Si-O-H & 50 & 115.0 \\
\hline
\end{tabular}

${ }^{\mathrm{a}} r_{0, \text { SiO }}=1.65 \AA$ must be used with the AMBER force field and $r_{0, \text { SiO }}=1.68 \AA$ with all other force fields due to different scaling of nonbond interactions of 1,4 bonded atoms (see text). 


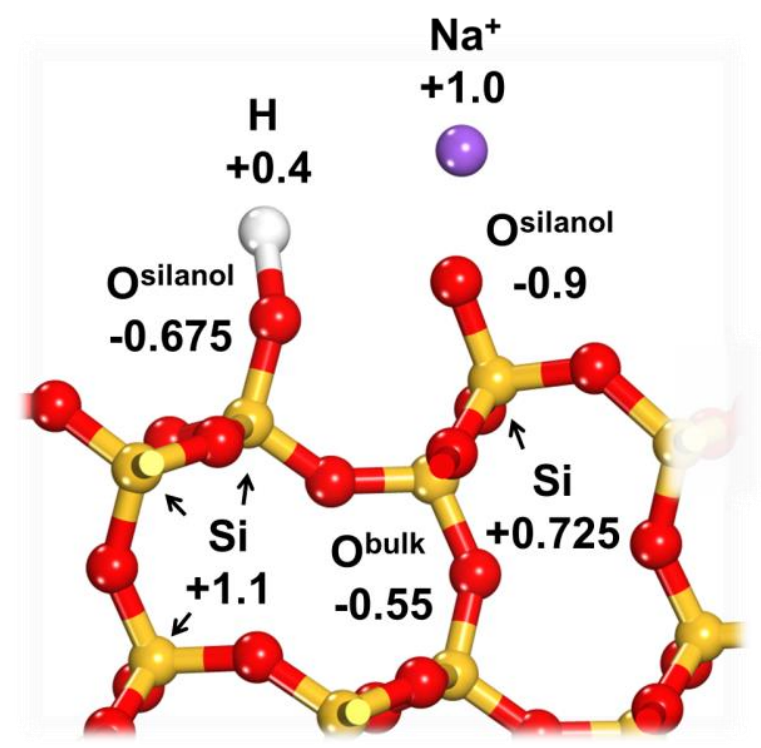

Figure 3. Atom types and atomic charges (in units of $e$ ) in the silica model. $\mathrm{O}^{\text {silanol }}$ and $\mathrm{Si}$ carry different charges when part of a siloxide group.

3.3. Derivation. The force field focuses on a chemical rationale for each parameter and aims at quantitative correlations with atomic-scale and bulk properties. ${ }^{46-48}$ This approach differs from "black box" DFT assignments and leads to the best possible accuracy as explained in the INTERFACE force field for a range of inorganic compounds. ${ }^{48}$ The full derivation and interpretation of parameters for silica is described in the Supporting Information (section S3) and important aspects are summarized in the following.

The atomic charges $q_{i}$ are vital to represent the balance of covalent versus ionic bonding precisely, and to enable consistency amongst parameters for silica, water, organic, and other inorganic compounds. Values of $q_{i}$ were assigned in agreement with electron deformation densities, dipole moments, an extended Born Model, comparisons to related compounds across the periodic table, as well as the known reactivity of $\mathrm{Si}-\mathrm{O}$ bonds in chemical reactions (Figure 3). ${ }^{46}$ Equal importance was given to the validation of Lennard-Jones parameters $\quad{ }_{i i}$ and ${ }_{i i}$ in 
comparison to experimentally measured surface properties, especially hydration energies (Table 3). ${ }^{47,48,55,109}$ Initial values for ${ }_{i i}$ and ${ }_{i i}$ were assigned on the basis of known atomic radii, ${ }^{110}$ polarizability, ${ }^{108}$ and the numbers of nonbonded neighbors in the nearest coordination shells. ${ }^{48}$ Accordingly, ii values of bulk and silanol oxygen atoms are distinguished while oxygen atoms in $\mathrm{Si}-\mathrm{OH}$ and $\mathrm{Si}_{-} \mathrm{O}^{-}$groups as well as all $\mathrm{Si}$ atoms could be treated the same (Figure 3).

Bonded parameters were assigned consistent with X-ray ${ }^{84,102,103}$ and IR/Raman data. ${ }^{97,98,111}$ Equilibrium bond lengths $r_{0, i j}$ and bond angles ${ }_{0, j i k}$ reflect X-ray measurements with minor adjustments (Table 4). ${ }^{84,102,103}$ Bond stretching and angle bending constants $k_{r, i j}$ and $k_{, i j k}$ were initially selected according to known vibration constants ${ }^{47,55,111}$ and refined to reproduce measured IR and Raman spectra of silica, using the Fourier transform of the velocity autocorrelation function as previously described. ${ }^{47}$

Finally, non-bonded parameters $\quad{ }_{i i}$ and ${ }_{i i}$ were refined to reproduce the cell parameters of $\alpha$-quartz and $\alpha$-cristobalite and hydration energies of $Q^{3}$ surfaces. ${ }^{72,91}$ Minor changes were made upon additional testing of the influence of all parameters through systematic variation within physically reasonable ranges in more than 500 individual calculations.

3.4. Validation of Structural, Vibrational, and Mechanical Properties. The force field yields an average Si-O bond length of $1.61 \pm 0.02 \AA$ for $\alpha$-cristobalite and $\alpha$-quartz in NPT simulations consistent with X-ray measurements of $1.61 \pm 0.01 \AA$ for all energy expressions. ${ }^{102,103}$ Computed cell parameters and gravimetric densities of $\alpha$-quartz and $\alpha$-cristobalite agree with measurements on average better than $1 \%$ for all energy expressions (Table 5 and Table S1). An exception is the $c$ dimension of $\alpha$-cristobalite that is computed to be up to $3.7 \%$ lower than in experiment (in PCFF only), related to different crystal packing and lower density compared to $\alpha$ - 
quartz. The introduction of additional specific force field types could eliminate this deviation but appeared unnecessary.

The model also reproduces vibration frequencies of silica in $\pm 20 \mathrm{~cm}^{-1}$ agreement with IR and Raman measurements (Figure 4). ${ }^{97,98,112,113}$ Strong bands at 950-1200 $\mathrm{cm}^{-1}$ correspond to asymmetric Si-O-Si stretching vibrations, weaker bands at $550-850 \mathrm{~cm}^{-1}$ to the symmetric Si-OSi stretching vibrations $v_{\mathrm{s}}$, and strong bands at $400-550 \mathrm{~cm}^{-1}$ to $\mathrm{O}-\mathrm{Si}-\mathrm{O}$ bending vibrations. The O-H stretching vibration of $\mathrm{SiOH}$ groups on silica surfaces near $3700 \mathrm{~cm}^{-1}$ is also reproduced in the simulation (not shown, see ref. ${ }^{97}$ for experimental data). The agreement of the major peaks at $\sim 1100 \mathrm{~cm}^{-1}, \sim 800 \mathrm{~cm}^{-1}$, and $\sim 480 \mathrm{~cm}^{-1}$ is very good for a simple, non-quantum mechanical model. ${ }^{\mathrm{r} 2}$ Although the intensities cannot be reproduced due to the lack of the full electronic structure, the vibrational signature appears clear enough to monitor frequency shifts in chemically different environments.

Computed elastic moduli of quartz and cristobalite are higher than values obtained by X-ray scattering and Brillouin spectroscopy measurements, ${ }^{89,102-104}$ a fact that is related to the superposition of extensive bonded terms and nonbond terms in the force field (see details in section S4). ${ }^{48,55,102,104,114-117}$ 
Table 5. Cell parameters of $\alpha$-quartz and $\alpha$-cristobalite according to X-ray data and NPT molecular dynamics simulation under standard conditions with PCFF (equation 2). Uncertainties are given in brackets in units of the last digit. Data for CVFF, CHARMM and AMBER energy expressions (equation 1) show even smaller deviations (Table S1).

$\begin{array}{lcccc} & \alpha \text {-quartz }(5 \times 5 \times 5 \text { super cell }) & \alpha \text {-cristobalite }(6 \times 6 \times 4 \text { super cell }) \\ \text { Property } & \text { X-ray } & \text { Simulation } & \text { X-ray } & \text { Simulation } \\ \text { Density }\left(\mathrm{g} / \mathrm{cm}^{\mathrm{b}}\right) & 2.66(4) & 2.68(2) & 2.32(4) & 2.43(2) \\ a(\AA) & 24.57(1) & 24.59(2) & 29.85(2) & 29.80(2) \\ b(\AA) & 24.57(1) & 24.59(2) & 29.85(2) & 29.80(2) \\ c(\AA) & 27.03(1) & 26.67(2) & 27.70(2) & 26.70(2) \\ \alpha\left({ }^{\circ}\right) & 90.0(0) & 90.0(0) & 90.0(0) & 90.0(0) \\ \beta\left({ }^{\circ}\right) & 90.0(0) & 90.0(0) & 90.0(0) & 89.9(0) \\ \gamma\left({ }^{\circ}\right) & 120.0(0) & 120.0(0) & 90.0(0) & 90.1(0) \\ 84,103 .{ }^{\mathrm{b}} \text { Ref. }{ }^{102} . & & & \end{array}$




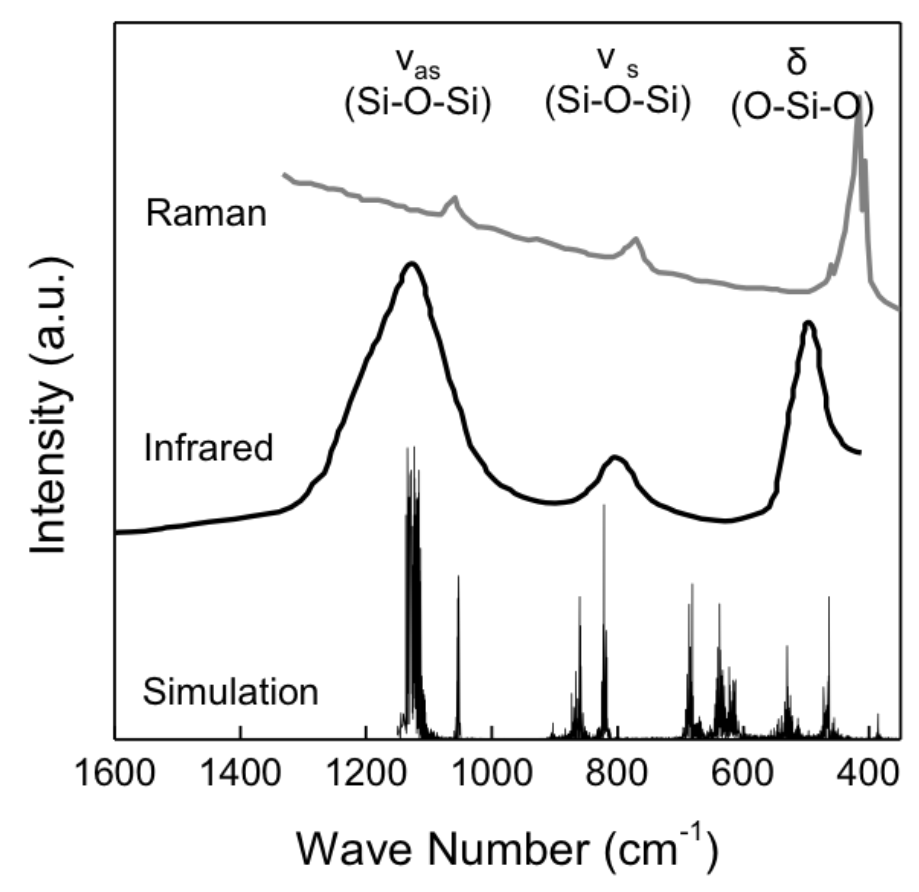

Figure 4. Vibration spectrum of $\alpha$-cristobalite (3D periodic crystal) in molecular dynamics simulation in comparison with experimental IR and Raman measurements (ref. ${ }^{98,112,113}$ ).

\section{Silica-Water Interfacial Properties}

The analysis of aqueous silica interfaces further establishes the reliability of the force field and provides new insight into the role of surface chemistry and $\mathrm{pH}$ for the structure of adsorbed water and electric double layers.

4.1. Heat of Immersion. The heat of immersion $H_{i m m}$ equals the enthalpy (or energy) released upon immersion of clean, vacuum-dried silica particles into water, and is suited to validate silica-water interactions (Figure 5). The enthalpy of immersion of pyrogenic silica was determined in calorimetric measurements as $H_{i m m}=160 \pm 5 \mathrm{~mJ} / \mathrm{m}^{2}$ at $300 \mathrm{~K}^{72}$ and computational results match this value within the uncertainty. However, it is important to choose equivalent 
silica surfaces in experiment and simulation due to the wide variability of surface chemistry and hydration energies between 100 and $1300 \mathrm{~mJ} / \mathrm{m}^{2}$ (see Table S2, Figure S1, and section S5). ${ }^{72,91-}$ 93,113,118,119 Pyrogenic silica is a suitable choice due to the absence of internal cavities and a welldefined area density of $4.7 \pm 0.1$ silanol groups per $\mathrm{nm}^{2}\left(\sim 80 \%\right.$ are $\mathrm{Q}^{3}$ type $) .{ }^{72,91}$ The measurements were carried out in ultrapure water at $\mathrm{pH}=7$ whereby the very low ionic strength $I<10^{-3} \mathrm{M}$ leads to negligible silanol ionization $(<1 \%) \cdot{ }^{37,39,54,56}$ Therefore, $\mathrm{Q}^{3}$ surface models with 4.7 silanol groups per $\mathrm{nm}^{2}$ and $0 \%$ surface ionization are appropriate for corresponding simulations (Figure 1a and section 2.2). The computed immersion energy of a $\mathrm{Q}^{3}$ surface with $4 \%$ ionization increased to $173 \mathrm{~mJ} / \mathrm{m}^{2}$ using the PCFF water model compared to $157 \mathrm{~mJ} / \mathrm{m}^{2}$ for a $0 \%$ ionized $\mathrm{Q}^{3}$ surface. The data indicate a negligible uncertainty, as an increment in ionization by $1 \%$ increases the computed immersion energy only $\sim 2.5 \%$.

The agreement of the calorimetric heat of immersion $H_{i m m}=160 \pm 5 \mathrm{~mJ} / \mathrm{m}^{2}$ with simulation results of 167,160 , and $157 \pm 2 \mathrm{~mJ} / \mathrm{m}^{2}$ at $300 \mathrm{~K}$ using SPC (flexible), TIP3P, and PCFF water models also shows that standard combination rules of 12-6 LJ and 9-6 LJ potentials describe silica-water interfacial interactions very well. The treatment of silica-organic and silicabiomolecular interfaces follows the same combination rules and enables similar performance. ${ }^{56}$ This example of thermodynamic consistency between phases also illustrates the foundation of the INTERFACE force field as a uniform simulation platform for all materials classes, which aims at the best possible reproduction of surface properties of individual solids, liquids, and gases to gain subsequent access to a multitude of interfaces in high accuracy without additional fit parameters. ${ }^{48}$ 


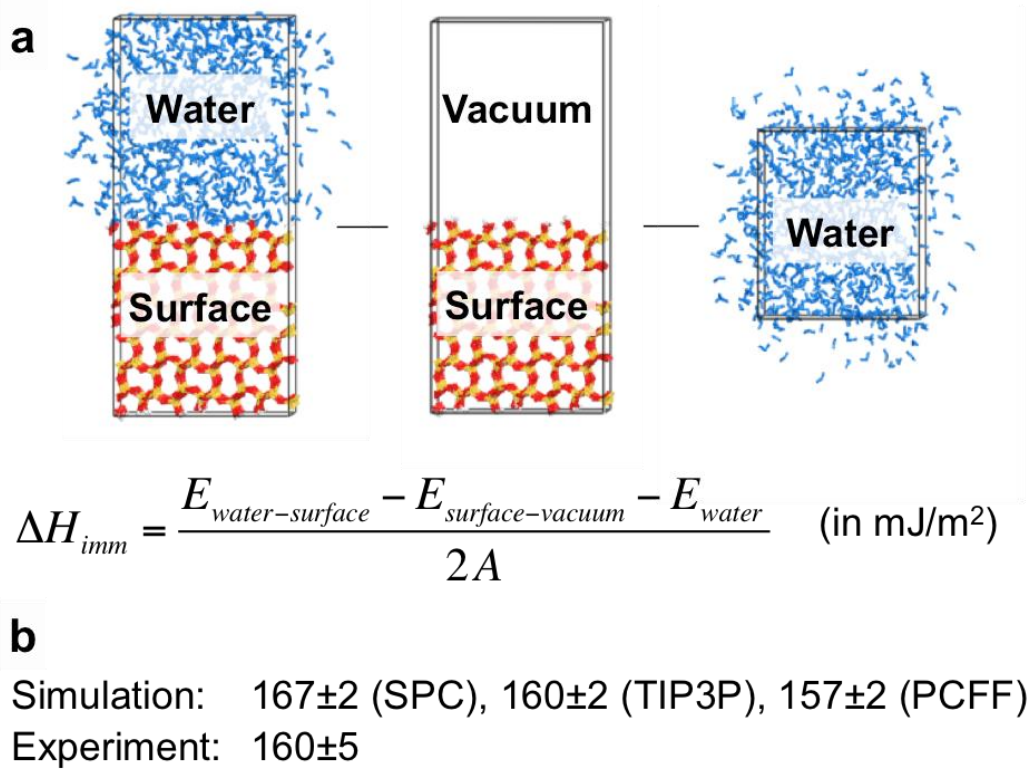

Figure 5. Heat of immersion of pyrogenic silica surfaces in water. (a) The computational procedure involves three molecular dynamics simulations. (b) Results for regular $\mathrm{Q}^{3}$ surfaces without ionization using different water models, and experimental results (ref. ${ }^{72,91}$ ).

4.2. Contact Angle. The comparison of measured and computed contact angles of water provides insight into differences between $\mathrm{Q}^{2}, \mathrm{Q}^{3}$, and $\mathrm{Q}^{4}$ surfaces (Figure 6) ${ }^{89}$ Clean silica surfaces with an average silanol area density between 9.4 and 4.7 per $\mathrm{nm}^{2}$ correspond to $\mathrm{Q}^{2}$, $\mathrm{Q}^{2} / \mathrm{Q}^{3}$, and $\mathrm{Q}^{3}$ surfaces and exhibit a contact angle $\theta=0^{\circ}$ (Figure 6a). These surfaces are strongly hydrophilic due to the formation of hydrogen bonds between surface $\mathrm{Si}-\mathrm{OH}$ groups and water molecules and thus not distinguishable by contact angles. Heat treatment from $200{ }^{\circ} \mathrm{C}$ to $1000{ }^{\circ} \mathrm{C}$ successively decreases the area density of surface silanol groups as a result of condensation of adjacent silanol groups in $\mathrm{Q}^{2}$ and $\mathrm{Q}^{3}$ environments to $\mathrm{Q}^{4}$ environments, and the surface wettability is reduced to $=42^{\circ}$ for $\mathrm{Q}^{4}$ surfaces (Figure 6b-d). The agreement between equilibrium contact angles in measurement ${ }^{89}$ and in molecular dynamics simulation for silica 
surfaces between $Q^{3}$ and $Q^{4}$ falls within $\pm 3^{\circ}$. The transition in surface chemistry was represented by models with $\sim 4.7,2.35,1.2$, and 0 silanol groups per $\mathrm{nm}^{2}$, and the silanol groups were nonionized to represent interfaces with deionized water (see sections 2.2 and 4.1)..$^{37,39,54,56}$ The data also agree with an empirical correlation between the equilibrium contact angle of silica/water/vapor interfaces and the area density of silanol groups $a_{S i O H}$ (normalized to $4.7 \mathrm{~nm}^{-2}$ for a regular $\mathrm{Q}^{3}$ surface) derived from silica powders (see section $\mathrm{S} 6$ for details): ${ }^{120}$

$$
\cos =0.257 \times\left(a_{S i O H} / 4.7 \mathrm{~nm}^{2}\right)+0.743 \text {. }
$$

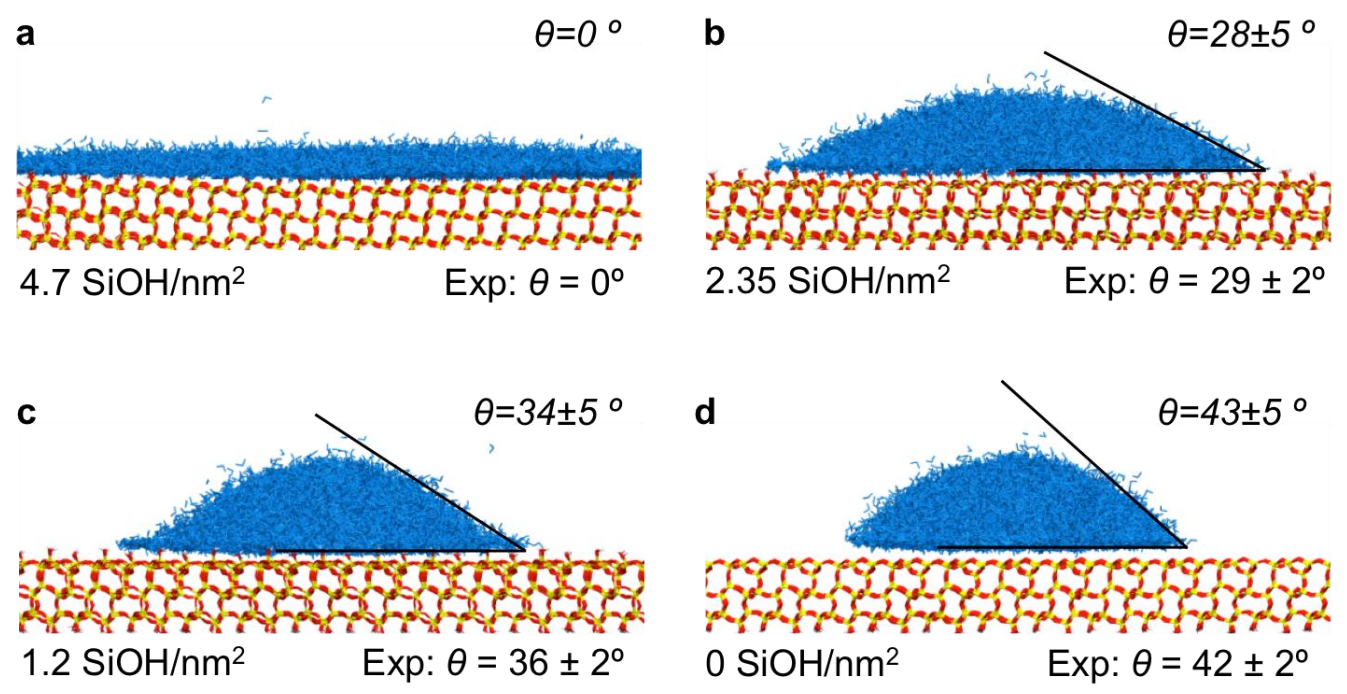

Figure 6. Water contact angles on charge-neutral silica surfaces ranging from $\mathrm{Q}^{3}$ to $\mathrm{Q}^{4}$ environments in simulation and experiment (ref. ${ }^{89}$ ). Increased content of $\mathrm{Q}^{4}$ environments from (a) to (d) represents surfaces annealed at temperatures between 200 and $1000{ }^{\circ} \mathrm{C}$.

4.3. Adsorption Isotherms. Adsorption isotherms are a further sensitive measure of water adsorption. ${ }^{92,94,95,121-123}$ The adsorbed amount of water as a function of the vapor pressure in the gas phase $P$ relative to the saturation vapor pressure $P_{0}$ was experimentally determined by Muster et al, ${ }^{90}$ Zhuravlev, ${ }^{88}$ and Baker et $\mathrm{al}^{95}$ using well-defined silica substrates with area 
densities of $\sim 4.6, \sim 4.6$, and $\sim 4.1$ silanol groups per $\mathrm{nm}^{2}$ (Figure 7 and Section S7). Adsorption isotherms computed by the Gibbs ensemble method for a non-ionized $\mathrm{Q}^{3}$ silica surface with 4.7 silanol groups per $\mathrm{nm}^{2}$ are in good agreement (Figure 7). The monolayer saturation pressure is consistently found between 0.2 and 0.3 times $P / P_{0}$, characterized by the onset of deviations from Langmuir-like adsorption isotherms. ${ }^{88,90,92,95,123}$

The simulations results also indicate structural details of adsorbed water. Notably, silanol groups constitute about half the water monolayer due to protrusion from the surface (Figure 1ac). Compared to "true" water monolayers on atomically smooth substrates $\left(16 \mu \mathrm{mol} / \mathrm{m}^{2}\right.$ or $\sim 10$ molecules per $\mathrm{nm}^{2}$ ), the amount of adsorbed water on $\mathrm{Q}^{3}$ silica at monolayer surface coverage is therefore lower $\left(7 \mu \mathrm{mol} / \mathrm{m}^{2}\right.$ or $\sim 4$ per $\mathrm{nm}^{2}$, more details in section S7). The simulation also shows that water molecules initially nucleate as clusters on the silica surface, especially near silanol groups. As a consequence, some water molecules are located in positions corresponding to a partial bilayer and trilayer starting at very low coverage (not counted in computed isotherms). Therefore, monolayers are not well defined (Figure S2), consistent with deviations of the shape of the adsorption isotherms from ideal Langmuir curves (Figure 7). Follow-up simulations can reveal more details for a variety of surface morphologies. 


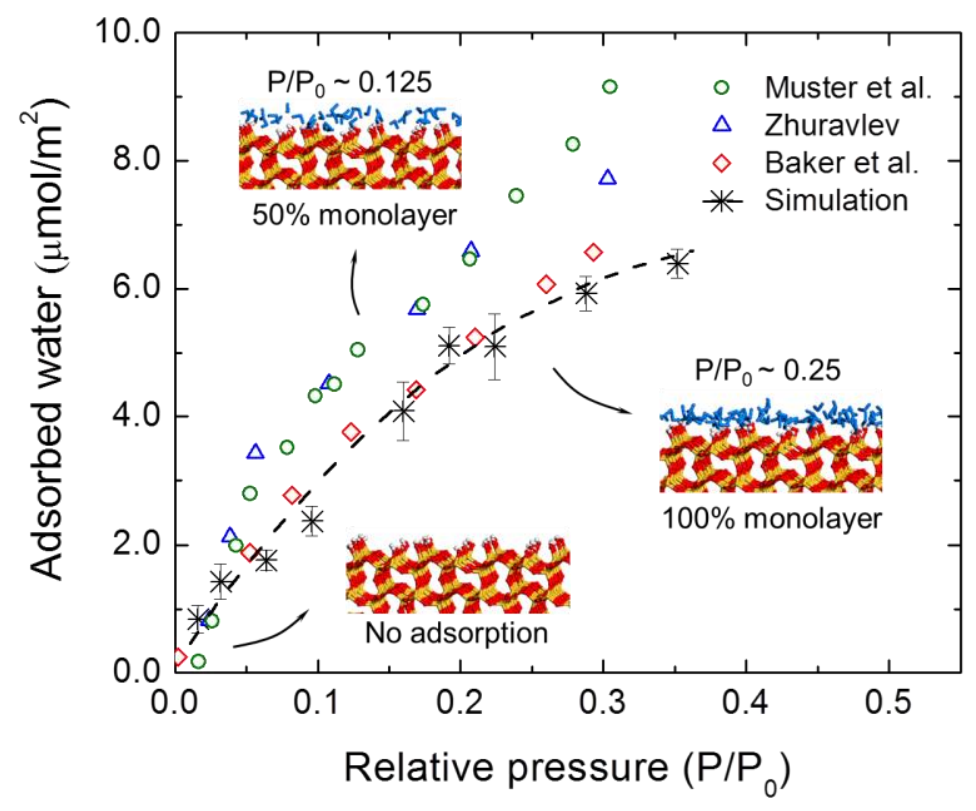

Figure 7. Adsorption isotherms of water according to simulation and measurements (refs. $\left.{ }^{88,90,95}\right)$. The computed adsorption isotherm on a non-ionic $\mathrm{Q}^{3}$ silica surface, highlighted by the dashed line, agrees with the lower range of measurements on silica particles containing 4.1 to 4.6 silanol groups per $\mathrm{nm}^{2}$. Simulations in the Gibbs ensemble show that adsorbed water clusters exceed monolayer thickness and continuous monolayers form at approximately 0.25 times the saturation vapor pressure $P_{0}$.

4.4. Role of Superficial Cations and Zeta Potential. Silica nanoparticles are often used in aqueous and physiological environments. Alkali cations neutralize the negative surface charge at $\mathrm{pH}>\mathrm{pzc}$ and are a key contributor to interfacial chemistry (Figure 1). As a result of the competitive interaction of alkali ions with surface siloxide groups and water molecules, a fraction of the cations dissociates into the aqueous phase and establishes an electric double layer composed of negatively charged siloxide ions and positively charged alkali ions. This principal 
behavior, as previously described by our team, ${ }^{19}$ can be seen in a density profile (Figure 8 ). The presence of several water layers of weakening intensity within $1 \mathrm{~nm}$ distance from the surface was found, and dissociation of cations past $0.3 \mathrm{~nm}$ from the surface is more frequent for less ionized surfaces. These "dissociated" cations are also most mobile upon application of a voltage and determine the outcome of zeta potential measurements.

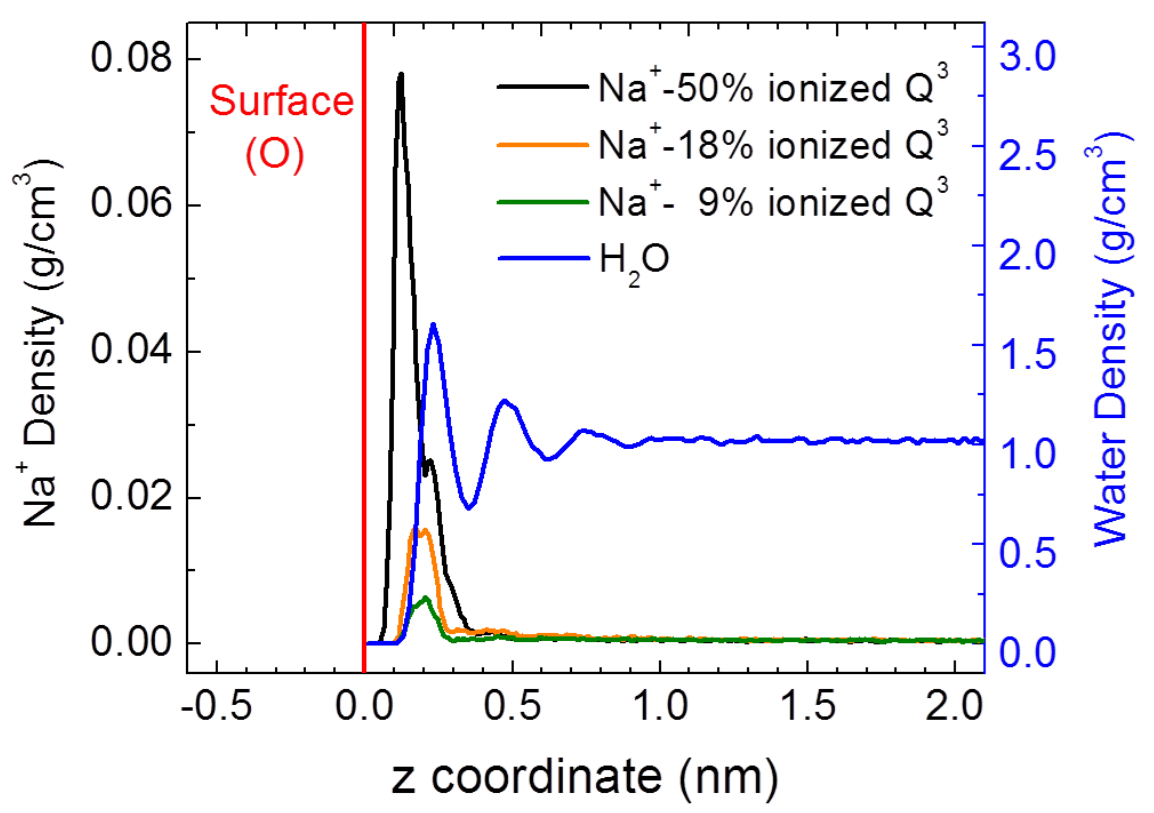

Figure 8. Density profile of water and sodium ions on a regular $\mathrm{Q}^{3}$ silica surface with different degree of ionization according to computation. The vertical red line indicates the average position of silanol oxygen atoms on the surface. The density profile of water is essentially independent from the sodium content and shows the formation of three distinctive layers of decreasing intensity. The profile approaches a uniform density of $1.00 \mathrm{~g} / \mathrm{cm}^{3}$ more than $1.0 \mathrm{~nm}$ away from the oxygen atoms of the surface. The distribution of sodium ions indicates major differences as a function of the degree of ionization: the penetration depth into solution is highest for lowest ionization (see Figure 9 for details). 
The penetration depth and area density of dissociated cations, i.e., cations that are more than $0.3 \mathrm{~nm}$ away from superficial oxygen atoms of $\mathrm{Si}(\mathrm{O}, \mathrm{Na})$ groups, are characteristic for the interfacial region, resulting in differential adsorption of peptides, drugs, surfactants, and polymers. The simulation shows that the total amount of dissociated cations in solution increases from 0 to $\sim 0.45 \mathrm{~nm}^{-2}$ when the surface ionization changes from $0 \%$ to $20 \%$, and then decreases to $\sim 0.3 \mathrm{~nm}^{-2}$ for higher ionization (Figure 9). Notably, at higher degree of ionization, the majority of alkali cations remains bound to the surface since mutual repulsion forces upon detachment would dramatically increase (Figures 8 and 9). ${ }^{19}$ The computed amount of free cation in solution with higher mobility correlate well with $\zeta$ potential measurements as a function of $\mathrm{pH}$ and particle size (Figure 10). Changes in surface ionization can result from a change in particle size (Figure 10a), from a change in $\mathrm{pH}$ (Figure 10b), or both (Figure 2).

These trends highlight the importance of the cation density per surface area and help understand swelling observations in experiment. ${ }^{32}$ Swelling has been particularly well studied for clay minerals, where cation densities per area similar to silica result in highest swelling and zeta potentials ( 0.5 to 1.2 cations per $\mathrm{nm}^{2}$, see section $\left.\mathrm{S} 8\right) .{ }^{124-126}$ These parallels suggest that the cation density per surface area is a key quantity for mineral surfaces with electric double layers and instrumental to understand properties of aqueous interfaces.

We also note that the force field opens up new opportunities for atomic-level monitoring of such tunable aqueous interfaces since surface ionization of silica and associated aqueous properties were disregarded in prior simulations (the relevance was first reported in refs. ${ }^{19,48}$ ). The accurate computation of immersion energies, contact angles, adsorption isotherms, and cation dissociation as a function of surface environment $\left(\mathrm{Q}^{4}, \mathrm{Q}^{3}, \mathrm{Q}^{2}\right), \mathrm{pH}$, and particle size 
therefore provides unique opportunities to understand and rationally design silica-based materials in combination with laboratory studies.

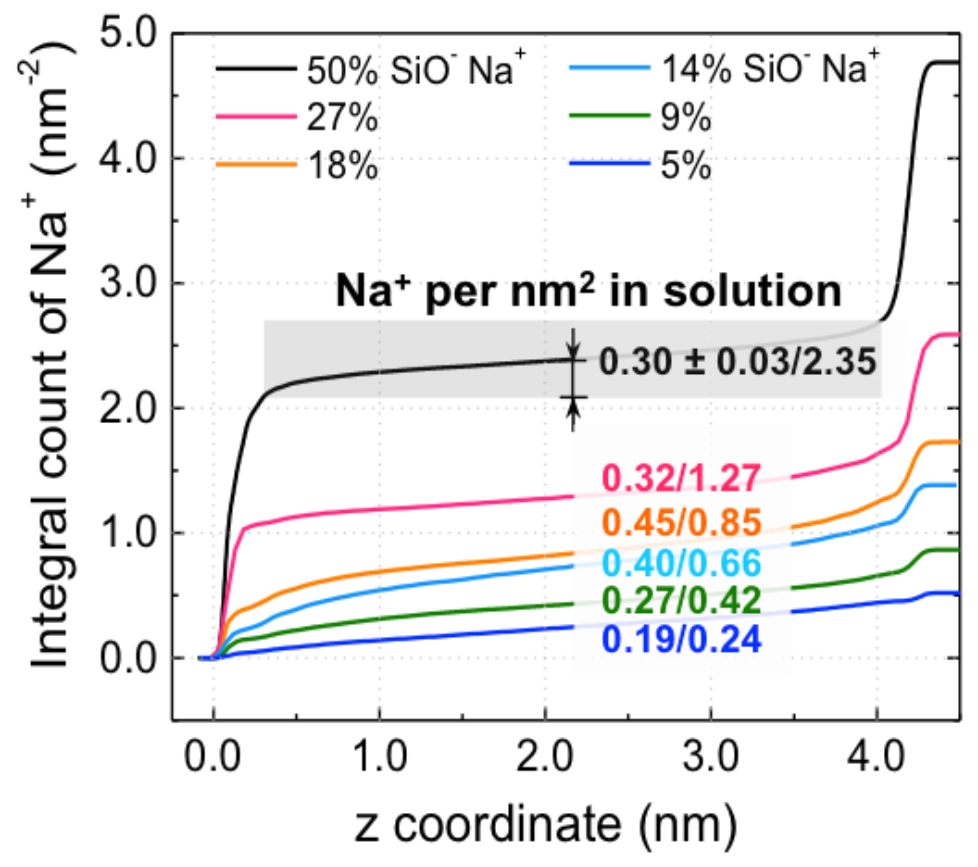

Figure 9. Integral count of sodium ions per $\mathrm{nm}^{2}$ between two aqueous $\mathrm{Q}^{3}$ silica surfaces as a function of distance from superficial oxygen atoms of $\mathrm{SiO}(\mathrm{H}, \mathrm{Na})$ groups for different percentage of silanol ionization according to atomistic simulation. The two numbers in each graph indicate the cumulative amount of dissociated sodium ions, defined as $>0.3 \mathrm{~nm}$ away from surface oxygen atoms, in relation to the total available amount of sodium ions per surface area. A higher total charge density causes less sodium dissociation, and leads to a maximum amount of dissociated sodium ions near $20 \%$ surface ionization $\left(\sim 0.9 \mathrm{SiO}^{-} \mathrm{Na}^{+}\right.$per $\left.\mathrm{nm}^{2}\right)$. The trend is consistent with zeta potentials, swelling observations on silica, and similar observations on clay minerals as a function of the area density of cations. 

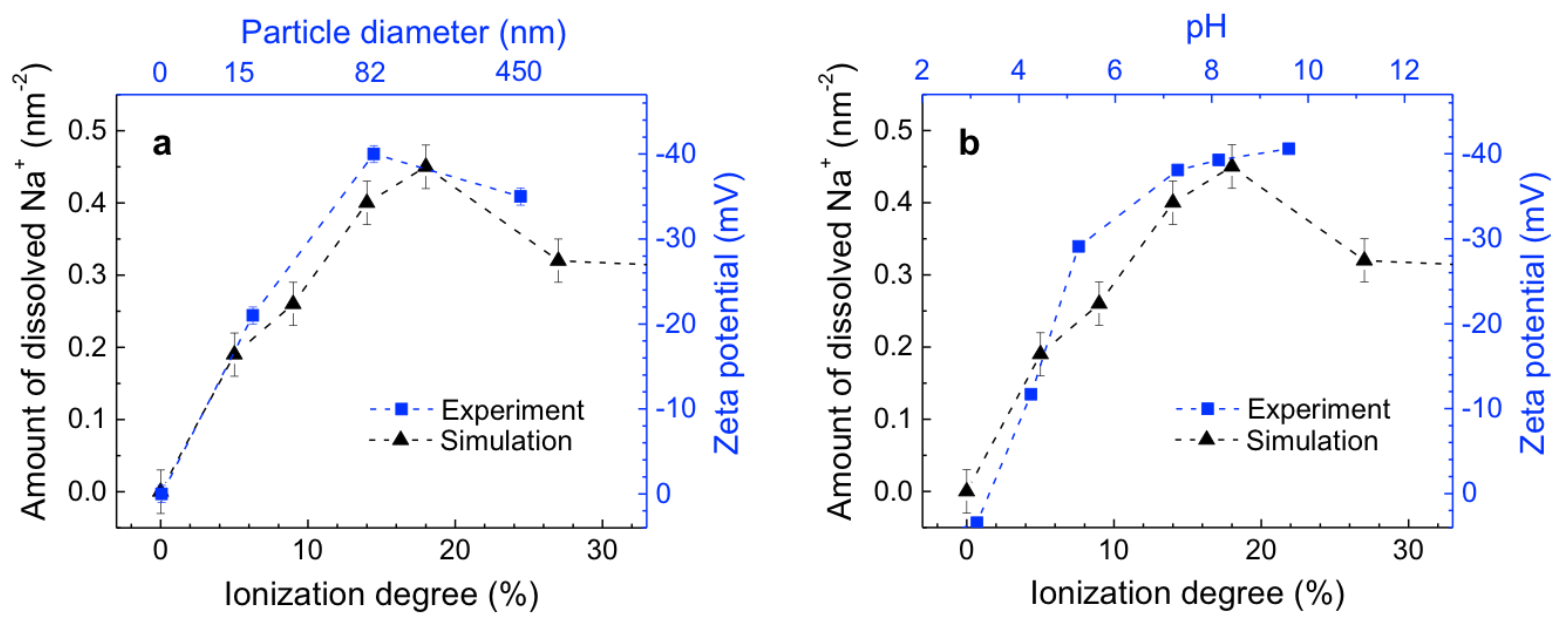

Figure 10. Correlation of the amount of dissociated cations per $\mathrm{nm}^{2}$ with zeta potentials as a function of particle size and $\mathrm{pH}$. (a) Larger particles exhibit more surface ionization and an increase in zeta potential up to a certain size, which correlates with the amount of dissolved ions in the computation (experimental data from our previous study ref. ${ }^{19}$ at $\mathrm{pH}=7$ ). (b) Higher $\mathrm{pH}$ values also increase surface ionization and the zeta potential up the limits known by surface titration ( $25 \%$, experimental data by Patwardhan et al. ${ }^{19}$ for particles of $82 \mathrm{~nm}$ size), and the amount of dissolved cations in the simulation is in near-quantitative agreement.

4.5. Comparison to Prior Force Fields, Limitations, and Opportunities. As mentioned in the introduction, several atomistic force fields for silica have been developed in the last 30 years (Table 1). The current force field eliminates major shortcomings and introduces the full range of variable surface chemistry for all types of silica, temperature pretreatment, $\mathrm{pH}$ values, and nanoparticle characteristics. Through careful analysis and interpretation of the parameters, predictive accuracy is achieved for structural and interfacial properties, as well as for specific recognition of biopolymers that corresponds to improvements from up to several $100 \%$ deviation 
in earlier models, or lack of feasibility altogether, to less than 5\% deviation from experiment. ${ }^{19,33-48,60-62,104}$

Remaining limitations of the model include the simulation of chemical reactions, a temperature range for best performance of $0-600 \mathrm{~K}$, and some uncertainty in mechanical properties due to conventions in harmonic force fields (see section S4). However, simplicity and broad compatibility of the new potential facilitate extensions for reactivity, such as dynamic proton distributions using constant $\mathrm{pH}$ molecular dynamics ${ }^{100}$ or augmentation of the harmonic bonded terms to Morse potentials to enable bond dissociation. Parameter adjustments at higher temperatures and pressures are possible to explore phase transformations of silica glasses. In addition, the silica parameters have become part of the INTERFACE force field that contains accurate parameters for further ring silicates, layered silicates, and aluminates. ${ }^{48}$ The derivation of reliable parameters for chemically similar zeolites and metal-organic frameworks is therefore also feasible with limited effort.

4.6. Anticipated Impacts on the Materials Chemistry Community. Silica is abundant in the biosphere and one of the most widely used materials, for example, in the form of porous glasses for gas and liquid separations, ${ }^{7,8}$ in nanoparticle form for drug delivery, ${ }^{12,14,15}$ as a filler material in composites, ${ }^{4-6}$ and in the form of core-shell nanoparticles for biomarkers and

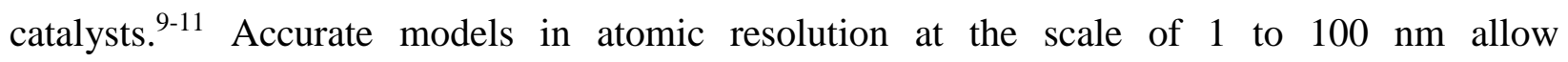
unprecedented insight into adsorption isotherms and the prediction of selective adsorption of gases, peptides, and drug molecules for various silica chemistries and morphologies..$^{19,20,25,29,56}$ Molecular-level information about recognition of silica nanoparticles (amorphous, crystalline etc) by biopolymers on cell surfaces as a function of $\mathrm{pH}$, ionic strength, and size can also help understand toxicity and support the development of treatments, e.g., for silicosis. ${ }^{127,128}$ The 
mechanism of silica mineralization by diatoms in vivo and in vitro has not yet been well understood and the synthesis of sophisticated silica nanostructures remains difficult. ${ }^{19,27,30}$ Simulation is one of few techniques that can provide nanometer-scale insight in $3 \mathrm{D}$ resolution coupled with experimental measurements, and extensions of the silica force field to silica precursors could provide more detailed insight and control. Silica particles of different origin are also used as fillers in polymer nanocomposites for automotive and aerospace applications, tires, and insulators. ${ }^{4-6}$ The understanding of silica interactions with various polymer segments has not yet far progressed, and accurate models from the nanoscale upwards can provide quantitative estimates of interfacial adhesion and affinity to various polymers, solvents, and plasticizers to optimize thermal and mechanical properties. Further, novel catalysts using mesoporous silica and silica-containing nanostructures have been made. ${ }^{9,10}$ The mechanism of silica dissolution and precipitation in the form of calcium-silicate-hydrate gels is also essential to understand cement hydration and develop sustainable building materials. ${ }^{129,130}$ These examples illustrate that a wide range of current and future applications of silica likely benefit from atomic level detail that accurate modeling and simulation can provide.

\section{Conclusions}

In this article we have introduced models for the full range of chemically variable, $\mathrm{pH}$ responsive silica surfaces, and presented a silica force field that reproduces atomic-scale, bulk, and interfacial properties in excellent agreement with experimental data. A database of 20 different representative surface model structures is provided on the basis of information about existing surface types, the influence of particle size, thermal modifications, $\mathrm{pH}$, and ionic strength (Table 2). Although models of silica surfaces must be customized for the area density of silanol groups, 
the fraction of ionized metal-siloxide groups, as well as surface topography to be of predictive value, many silica nanoparticles and porous glasses can be approximated as $\mathrm{Q}^{3}$ silica surfaces with customized degree of ionization. Thereby, small differences in silanol number or degree of ionization have no major effect.

New findings on aqueous silica interfaces are also reported based on observations from Monte Carlo and Molecular Dynamics simulations. The mechanism of the formation of water layers from the gas phase involves nucleation near silanol groups and the creation of diffuse water multilayers. A key parameter of bulk aqueous silica interfaces is the number of dissociated cations per surface area, a factor that correlates with experimentally measured zeta potentials.

The force field for silica is conceptually simple and involves only few parameters with clearly defined interpretation that can be regarded as an atomic-level code for its interfacial properties. Several shortcomings in prior force fields are resolved by introducing full mobility of atoms, chemically justified polarity, surface environments from $\mathrm{Q}^{2}$ to $\mathrm{Q}^{4}$, incorporation of ionization as a function of $\mathrm{pH}$ and particle size, validation of hydration properties, and contact angles. As a result, deviations up to several $100 \%$ in previous models are reduced to less than $10 \%$ and the silica parameters are integrated in common biomolecular and materials oriented force fields such as AMBER, CHARMM, CVFF, PCFF, COMPASS, INTERFACE, including flexible SPC and TIP3P water models. Possible uses include computational guidance in the design of silica nanostructures in atomic resolution for drug delivery, biomarkers, catalysts, environmental remediation, membranes for gas separation, and filler materials for composites. Predictions of the selective adsorption of highly specific biomolecules are described in a followon paper. ${ }^{56}$ The parameters can also be extended to zeolites, metal organic frameworks, and reactive potentials. 


\section{Acknowledgement}

We acknowledge support from the Air Force Research Laboratory, UES, Inc., the Air Force Office of Scientific Research (F. S. E. and H. H. via FA8650-09-D-5037, C. C. P. via FA9550-10-1-0024 and FA9550-13-1-0040), the National Science Foundation (DMR-0955071), the University of Akron, and the Ohio Supercomputing Center for the allocation of computational resources.

Supporting Information Available: Additional Figures and Tables, a history of earlier force fields, information on silica surface models, derivation and interpretation of force field parameters, mechanical properties, heat of immersion, contact angles, adsorption isotherms of water, parallels in swelling of silica and clay minerals, and complete details of computational and experimental methods are given. A silica surface model database containing coordinate files and descriptions of more than twenty models of silica and representative surfaces is provided in simulation-ready format (car/mdf, lammps05, and pdb/psf), as well as two utility programs to build pdb/psf files for silica-solution interfaces. This information is available free of charge at http://www.acs.org.

\section{References}

(1) Hoffmann, F.; Cornelius, M.; Morell, J.; Froba, M. Angew. Chem.-Int. Edit. 2006, $45,3216$.

(2) Iler, R. K. The Chemistry of Silica: Solubility, Polymerization, Colloid and Surface Properties, and Biochemistry; John Wiley \& Sons: New York, 1979. 
(3) Slowing, II; Trewyn, B. G.; Giri, S.; Lin, V. S. Y. Adv. Funct. Mater. 2007, 17, 1225.

(4) Chattopadhyay, D. K.; Webster, D. C. Prog. Polym. Sci. 2009, 34, 1068.

(5) Paul, D. R.; Robeson, L. M. Polymer 2008, 49, 3187.

(6) Jouault, N.; Vallat, P.; Dalmas, F.; Said, S.; Jestin, J.; Boue, F. Macromolecules 2009, 42, 2031.

(7) Li, J.-R.; Kuppler, R. J.; Zhou, H.-C. Chem. Soc. Rev. 2009, 38, 1477.

(8) Markovic, A.; Stoltenberg, D.; Enke, D.; Schlunder, E. U.; Seidel-Morgenstern, A. J. Membrane Sci. 2009, 336, 17.

(9) Deng, Y.; Cai, Y.; Sun, Z.; Liu, J.; Liu, C.; Wei, J.; Li, W.; Liu, C.; Wang, Y.; Zhao, D. J. Am. Chem. Soc. 2010, 132, 8466.

(10) Joo, S. H.; Park, J. Y.; Tsung, C.-K.; Yamada, Y.; Yang, P.; Somorjai, G. A. Nature Mater. 2009, 8, 126.

(11) Chaudhuri, R. G.; Paria, S. Chem. Rev. 2012, 112, 2373.

(12) Mackowiak, S. A.; Schmidt, A.; Weiss, V.; Argyo, C.; von Schirnding, C.; Bein, T.; Bräuchle, C. Nano Lett. 2013, 13, 2576.

(13) Sanchez, C.; Julian, B.; Belleville, P.; Popall, M. J. Mater. Chem. 2005, 15, 3559.

(14) Ariga, K.; Vinu, A.; Yamauchi, Y.; Ji, Q.; Hill, J. P. Bull. Chem. Soc. Japan 2012, 85,1 .

(15) Ambrogio, M. W.; Thomas, C. R.; Zhao, Y. L.; Zink, J. I.; Stoddartt, J. F. Acc. Chem. Res. 2011, 44, 903.

(16) Hildebrand, M. Chem. Rev. 2008, 108, 4855.

(17) Sarthou, G.; Timmermans, K. R.; Blain, S.; Treguer, P. J. Sea Res. 2005, 53, 25. 
(18) Sumper, M.; Brunner, E. Adv. Funct. Mater. 2006, 16, 17.

(19) Patwardhan, S. V.; Emami, F. S.; Berry, R. J.; Jones, S. E.; Naik, R. R.;

Deschaume, O.; Heinz, H.; Perry, C. C. J. Am. Chem. Soc. 2012, 134, 6244.

(20) Puddu, V.; Perry, C. C. ACS Nano 2012, 6, 6356.

(21) Kröger, N.; Deutzmann, R.; Sumper, M. Science 1999, 286, 1129.

(22) Kröger, N.; Lorenz, S.; Brunner, E.; Sumper, M. Science 2002, 298, 584.

(23) Kaehr, B.; Townson, J. L.; Kalinich, R. M.; Awad, Y. H.; Swartzentruber, B. S.;

Dunphy, D. R.; Brinker, C. J. Proc. Natl. Acad. Sci. U.S.A. 2012, 109, 17336.

(24) Patwardhan, S. V. Chem. Comm. 2011, 47, 7567.

(25) Rimola, A.; Costa, D.; Sodupe, M.; Lambert, J.-F.; Ugliengo, P. Chem. Rev. 2013, $113,4216$.

(26) Cha, J. N.; Stucky, G. D.; Morse, D. E.; Deming, T. J. Nature 2000, 403, 289.

(27) Muller, W. E. G.; Schroder, H. C.; Burghard, Z.; Pisignano, D.; Wang, X. H. Chem. Eur. J. 2013, 19, 5790.

(28) Patwardhan, S. V.; Clarson, S. J.; Perry, C. C. Chem. Commun. 2005, 1113.

(29) Perry, C. C.; Patwardhan, S. V.; Deschaume, O. Biochem. Soc. Trans. 2009, 37, 687.

(30) Ogasawara, W.; Shenton, W.; Davis, S. A.; Mann, S. Chem. Mater. 2000, 12, 2835.

(31) Stober, W.; Fink, A.; Bohn, E. J. Colloid Interface Sci. 1968, $26,62$.

(32) Vigil, G.; Xu, Z. H.; Steinberg, S.; Israelachvili, J. J. Colloid Interface Sci. 1994, $165,367$. 
(33) Sanders, M. J.; Leslie, M.; Catlow, C. R. A. J. Chem. Soc.-Chem. Commun. 1984, 1271.

(34) van Beest, B. W. H.; Kramer, G. J. Phys. Rev. Lett. 1990, 64, 1955.

(35) Hill, J. R.; Sauer, J. J. Phys. Chem. 1994, 98, 1238.

(36) Cruz-Chu, E. R.; Aksimentiev, A.; Schulten, K. J. Phys. Chem. B 2006, 110, 21497.

(37) Hassanali, A. A.; Singer, S. J. J. Phys. Chem. B 2007, 111, 11181.

(38) Hassanali, A. A.; Zhang, H.; Knight, C.; Shin, Y. K.; Singer, S. J. J. Chem.

Theory Comput. 2010, 6, 3456.

(39) Lopes, P. E. M.; Murashov, V.; Tazi, M.; Demchuk, E.; MacKerell, A. D. J. Phys. Chem. B 2006, 110, 2782.

(40) Butenuth, A.; Moras, G.; Schneider, J.; Koleini, M.; Köppen, S.; Meißner, R.;

Wright, L. B.; Walsh, T. R.; Ciacchi, L. C. Phys. Status Solidi B 2012, 249, 292.

(41) Flikkema, E.; Bromley, S. T. Chem. Phys. Lett. 2003, 378, 622.

(42) Goumans, T. P.; Wander, A.; Brown, W. A.; Catlow, C. R. Phys. Chem. Chem. Phys. 2007, 9, 2146.

(43) Skelton, A. A.; Fenter, P.; Kubicki, J. D.; Wesolowski, D. J.; Cummings, P. T. J. Phys. Chem. C 2011, 115, 2076.

(44) Hill, J. R.; Sauer, J. J. Phys. Chem. 1995, 99, 9536.

(45) Chenoweth, K.; van Duin, A. C. T.; Goddard III, W. A. J. Phys. Chem. A. 2008, $112,1040$.

(46) Heinz, H.; Suter, U. W. J. Phys. Chem. B 2004, 108, 18341. 
(47) Heinz, H.; Koerner, H.; Anderson, K. L.; Vaia, R. A.; Farmer, B. L. Chem. Mater. 2005, 17,5658 .

(48) Heinz, H.; Lin, T.-J.; Mishra, R. K.; Emami, F. S. Langmuir 2013, 29, 1754.

(49) Zhuravlev, L. T. Colloids Surf., A 2000, 173, 1.

(50) Bolt, G. H. J. Phys. Chem. 1957, 61, 1166.

(51) Sonnefeld, J. J. Colloid Interface Sci. 1996, 183, 597.

(52) Tadros, T. F.; Lyklema, J. J. Electroanal. Chem. Interfacial Electrochem. 1968, $17,267$.

(53) Zerrouk, R.; Foissy, A.; Mercier, R.; Chevallier, Y.; Morawski, J.-C. J. Colloid Interface Sci. 1990, 139, 20.

(54) Heinz, H.; Vaia, R. A.; Farmer, B. L. J. Chem. Phys. 2006, 124, 224713.

(55) Mishra, R. K.; Flatt, R. J.; Heinz, H. J. Phys. Chem. C 2013, 117, 10417.

(56) Emami, F. S.; Puddu, V.; Berry, R. J.; Varshney, V.; Patwardhan, S. V.; Perry, C. C.; Heinz, H. Submitted.

(57) MacKerell, A. D., Jr.; Bashford, D.; Bellott, M.; Dunbrack, R. L., Jr.; Evanseck, J. D.; Fields, M. J.; Fischer, S.; Gao, J.; Guo, H.; Ha, S.; Joseph-McCarthy, D.; Kuchnir, L.; Kuczera, K.; Lau, F. T. K.; Mattos, C.; Michnick, S.; Ngo, T.; Nguyen, D. T.; Prodhom, B.; Reiher, W. E., III; Roux, B.; Schlenkrich, M.; Smith, J. C.; Stote, R.; Straub, J.; Watanabe, D.; Wiórkiewicz-Kuczera, J.; Yin, D.; Karplus, M. J. Phys. Chem. B 1998, 102, 3586.

(58) Dauber-Osguthorpe, P.; Roberts, V. A.; Osguthorpe, D. J.; Wolff, J.; Genest, M.; Hagler, A. T. Proteins: Struct., Funct., Genet. 1988, 4, 31.

(59) Pearlman, D. A.; Case, D. A.; Caldwell, J. W.; Ross, W. S.; Cheatham, T. E.;

DeBolt, S.; Ferguson, D.; Seibel, G.; Kollman, P. Comput. Phys. Commin. 1995, 91, 1. 
(60) Maple, J. R.; Thacher, T. S.; Dinur, U.; Hagler, A. T. Chem. Des. Autom. News

1990, 5,5 .

(61) Sun, H. J. Comput. Chem. 1994, 15, 752.

(62) Sun, H. Macromolecules 1995, $28,701$.

(63) Sun, H. J. Phys. Chem. B 1998, 102, 7338.

(64) Ngo, T.; Schwarzenbach, D. Acta Crystallogr., Sect. A: Cryst. Phys., Diffr.,

Theor., Gen. Crystallogr. 1979, A35, 658.

(65) Lewis, J.; Schwarzenbach, D. Acta Crystallogr., Sect. A: Cryst. Phys., Diffr., Theor., Gen. Crystallogr. 1982, A38, 733.

(66) Belokonewa, E. L.; Gubina, Y. K.; Forsyth, J. B.; Brown, P. J. J. Phys. Chem.

Min. 2002, 29, 430.

(67) Abendroth, R. P. J. Colloid Interface Sci. 1970, 34, 591.

(68) Yates, D. E.; Healy, T. W. J. Colloid Interface Sci. 1976, 55, 9.

(69) Milonjić, S. K. Colloids Surf. 1987, 23, 301.

(70) House, W. A.; Orr, D. R. J. Chem. Soc., Faraday Trans. 1992, 88, 233.

(71) Méndez, A.; Bosch, E.; Rosés, M.; Neue, U. D. J. Chromatogr. A 2003, 986, 33.

(72) Taylor, J. A. G.; Hockey, J. A. J. Phys. Chem. 1966, 70, 2169.

(73) Oren, E. E.; Tamerler, C.; Sahin, D.; Hnilova, M.; Seker, U. O. S.; Sarikaya, M.; Samudrala, R. Bioinformatics 2007, 23, 2816.

(74) Oren, E. E.; Notman, R.; Kim, I. W.; Spencer, E. J.; Walsh, T. R.; Samudrala, R.; Tamerler, C.; Sarikaya, M. Langmuir 2010, 26, 11003.

(75) Eteshola, E.; Brillson, L. J.; Lee, S. C. Biomol. Eng. 2005, 22, 201. 
(76) Naik, R. R.; Brott, L. L.; Clarson, S. J.; Stone, M. O. J. Nanosci. Nanotechnol.

2002, 2, 95 .

(77) Naik, R. R.; Stringer, S. J.; Agarwal, G.; Jones, S. E.; Stone, M. O. Nature Mater.

2002, $1,169$.

(78) Ruan, L.; Ramezani-Dakhel, H.; Chiu, C. Y.; Zhu, E.; Li, Y.; Heinz, H.; Huang, Y. Nano Lett. 2013, 13, 840.

(79) Heinz, H.; Farmer, B. L.; Pandey, R. B.; Slocik, J. M.; Patnaik, S. S.; Pachter, R.; Naik, R. R. J. Am. Chem. Soc. 2009, 131, 9704.

(80) Feng, J.; Pandey, R. B.; Berry, R. J.; Farmer, B. L.; Naik, R. R.; Heinz, H. Soft Matter 2011, 7, 2113.

(81) Feng, J.; Slocik, J. M.; Sarikaya, M.; Naik, R. R.; Farmer, B. L.; Heinz, H. Small 2012, 8, 1049.

(82) Fu, X.; Wang, Y.; Huang, L.; Sha, Y.; Gui, L.; Lai, L.; Tang, Y. Adv. Mater. 2003, $15,902$.

(83) Tamerler, C.; Sarikaya, M. Acta Biomater. 2007, 3, 289.

(84) Silica: Physical Behavior, Geochemistry, and Materials Applications; Heaney, P. J., Prewitt, C. T., Gibbs, G. V., eds., In: Reviews in Mineralogy, Vol. 29; Mineralogical Society of America: New Jersey, USA, 1994.

(85) Gommes, C. J.; Blacher, S.; Pirard, J.-P.; Scherer, G. W. J. Sol-Gel Sci. Technol. 2007, 44, 211.

(86) Zhang, H. Y.; Dunphy, D. R.; Jiang, X. M.; Meng, H.; Sun, B. B.; Tarn, D.; Xue, M.; Wang, X.; Lin, S. J.; Ji, Z. X.; Li, R. B.; Garcia, F. L.; Yang, J.; Kirk, M. L.; Xia, T.; Zink, J. I.; Nel, A.; Brinker, C. J. J. Am. Chem. Soc. 2012, 134, 15790. 
(87) Zhuravlev, L. T. Langmuir 1987, 3, 316.

(88) Zhuravlev, L. T. Colloids Surf., A 1993, 74, 71.

(89) Lamb, R. N.; Furlong, D. N. J. Chem. Soc., Faraday Trans. 1 F 1982, 78, 61.

(90) Muster, T. H.; Prestidge, C. A.; Hayes, R. A. Colloids Surf., A 2001, 176, 253.

(91) Balard, H.; Donnet, J.-B.; Oulanti, H.; Gottschalk-Gaudig, T.; Barthel, H.

Colloids Surf., A 2011, 378, 38.

(92) Douillard, J. M.; Elwafir, M.; Partyka, S. J. Colloid Interface Sci. 1994, 164, 238.

(93) Partyka, S.; Rouquerol, F.; Rouquerol, J. J. Colloid Interface Sci. 1979, 68, 21.

(94) Boyd, G. E.; Livingston, H. K. J. Am. Chem. Soc. 1942, 64, 2383.

(95) Baker, F. S.; Sing, K. S. W. J. Colloid Interface Sci. 1976, 55, 605.

(96) Dorémieux-Morin, C.; Heeribout, L.; Dumousseaux, C.; Fraissard, J.; Hommel, H.; Legrand, A. P. J. Am. Ceram. Soc. 1996, 118, 13040.

(97) Burneau, A.; Barrès, O.; Gallas, J. P.; Lavalley, J. C. Langmuir 1990, 6, 1364.

(98) Handke, M.; Mozgawa, W. Vib. Spectrosc. 1993, 5, 75.

(99) Liang, M.-K.; Deschaume, O.; Patwardhan, S. V.; Perry, C. C. J. Mater. Chem.

2011, 21,80 .

(100) Wallace, J. A.; Shen, J. K. J. Chem. Phys. 2012, 137, 184105.

(101) Heinz, H.; Castelijns, H. J.; Suter, U. W. J. Am. Chem. Soc. 2003, 125, 9500.

(102) Dera, P.; Lazarz, J. D.; Prakapenka, V. B.; Barkley, M.; Downs, R. T. Phys. Chem. Miner. 2011, 38, 517.

(103) Kihara, K. Eur. J. Mineral. 1990, 2, 63.

(104) Heinz, H.; Vaia, R. A.; Farmer, B. L.; Naik, R. R. J. Phys. Chem. C 2008, 112, 17281. 
(105) Holleman, A. F.; Wiberg, E. Inorganic Chemistry; Academic Press: New York, 1995.

(106) Beglov, D.; Roux, B. J. Chem. Phys 1994, 100, 9050.

(107) Joung, I. S.; Cheatham, T. E. J. Phys. Chem. B 2008, 112, 9020.

(108) Halgren, T. A. J. Am. Chem. Soc. 1992, 114, 7827.

(109) Heinz, H.; Vaia, R. A.; Farmer, B. L. J. Chem. Phys 2006, 124, 224713.

(110) Batsanov, S. S. Inorg. Mater. 2001, 37, 871.

(111) CRC Handbook of Chemistry and Physics 89th, Lide, D. R., ed.; CRC Press: Boca Raton, FL, 2008.

(112) Finnie, K. S.; Thompson, J. G.; Withers, R. L. J. Phys. Chem. Solids 1994, 55, 23.

(113) Kingma, K. J.; Hemley, R. J. Am. Mineral. 1994, 79, 269.

(114) Zartman, G. D.; Liu, H.; Akdim, B.; Pachter, R.; Heinz, H. J. Phys. Chem. C 2010, 114, 1763.

(115) Heinz, H. J. Comput. Chem. 2010, 31, 1564.

(116) Oliver, W. C.; Pharr, G. M. J. Mater. Res. 1992, 7, 1564.

(117) Levien, L.; Prewitt, C. T.; Weidner, D. J. Am. Mineral. 1980, 65, 920.

(118) Kondo, S.; Fujiwara, H.; Ichii, T.; Tsuboi, I. J. Chem. Soc., Faraday Trans. I 1979, 75, 646.

(119) Donnet, J.-B.; Balard, H.; Nedjari, N.; Hamdi, B.; Barthel, H.; G.-G., T. J. Colloid Interface Sci. 2008, 328, 15.

(120) Knözinger, H. In The Hydrogen Bonds: III Dynamics, Thermodynamics and Special Systems; Schuster, P., Zundel, G., Sandorfy, C., Eds. North Holland, Amsterdam, 1976, p 1329. 
(121) Hackerman, N.; Hall, A. C. J. Phys. Chem. 1958, 62, 1212.

(122) Staszczuk, P. Chromatographia 1985, 20, 724.

(123) Helmy, A. K.; de Bussetti, S. G.; Ferreiro, E. A. Appl. Surf. Sci. 2007, 253, 6878.

(124) Heinz, H. Clay Miner. 2012, 47, 205.

(125) Fu, Y. T.; Heinz, H. Philos. Mag. 2010, 90, 2415.

(126) Schoonheydt, R. A.; Johnston, C. T. In The Surface Properties of Clay Minerals;

Brigatti, M. F., Mottana, A., Eds.; The European Mineralogical Union: 2011.

(127) Gonzalez, L.; Lukamowicz-Rajska, M.; Thomassen, L. C. J.; Kirschhock, C. E. A.; Leyns, L.; Lison, D.; Martens, J. A.; Elhajouji, A.; Kirsch-Volders, M. Nanotoxicology 2014, 8,876 .

(128) Kishore, U.; Greenhough, T. J.; Waters, P.; Shrive, A. K.; Ghai, R.; Kamran, M. F.; Bernal, A. L.; Reid, K. B. M.; Madan, T.; Chakraborty, T. Molecular Immunology 2006, 43, 1293.

(129) Scrivener, K. L.; Nonat, A. Cem. Concr. Res. 2011, 41, 651.

(130) Richardson, I. G. Cem. Concr. Res. 2008, 38, 137. 


\section{TOC Illustration}
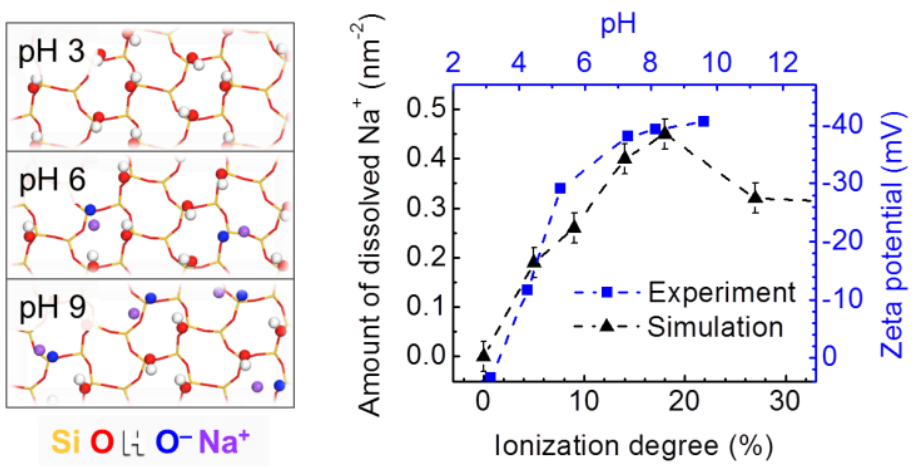